\title{
VOTO IDEOLÓGICO, ¿POR QUÉ LOS LATINOAMERICANOS VOTAN POR LA IZQUIERDA O LA DERECHA?
}

\author{
IDEOLOGICAL VOTE: WHY DO LATIN AMERICANS \\ VOTE FOR THE LEFT OR THE RIGHT?
}

\section{LE VOTE IDÉOLOGIQUE: QU'EST-CE QUI MÈNE LES LATINOAMÉRICAINS À VOTER POUR LA GAUCHE OU POUR LA DROITE?}

\author{
Mario Alejandro Torrico Terán \\ FLACSO-México \\ mario.torrico@flacso.edu.mx \\ Diego Solís Delgadillo \\ El Colegio de San Luis A.C. \\ diego.solis@flacso.edu.mx
}

\begin{abstract}
Resumen: La discusión sobre las causas de los giros a la izquierda y a la derecha en América Latina es extensa y ha multiplicado los estudios electorales comparados en la región. Sin embargo, debido a que se les analiza de forma aislada, su contribución para entender por qué la gente vota por las opciones de uno u otro lado del espectro ideológico es reducida. En este trabajo examinamos el voto ideológico de los latinoamericanos entre 1996 y 2016, y encontramos que las posiciones a favor o en contra de Estados Unidos y la ideología de los votantes son los principales factores que lo explican, aunque también tienen importancia la clase social, la confianza en las instituciones políticas, la ideología del gobierno en funciones y el sexo del votante. La pertenencia indígena favorece el voto por las opciones de izquierda cuando previamente se ha politizado esa división. No obstante, existen variaciones nacionales muy grandes respecto a las tendencias regionales, lo que evidencia la heterogeneidad de la región.
\end{abstract}

Palabras clave: América Latina, voto ideológico, comportamiento electoral, izquierda, derecha. 
Aвstract: The discussion of the causes of the turns to the left or the right in Latin America is an extensive one, and comparative electoral studies in the region have multiplied. However, due to the fact that they are analyzed in isolation, their contribution to understanding why people vote for the alternatives at one end of the ideological spectrum or the other is limited. This paper examines the ideological voting behavior of Latin Americans between 1996 and 2016, and we find that positions for or against the United States and the ideology of voters are the principal factors to explain this, together with social class, trust in political institutions, the ideology of the current government and the gender of the voter. Belonging to an indigenous group tends to favor a vote for left-wing alternatives when this division has previously been politicized. However, there are very large national variations compared to the regional trends, indicating that it is a very heterogeneous region.

Keywords: Latin America, ideological vote, electoral behavior, left, right.

\section{Traducción de GonZalo Celorio Morayta}

RÉSumÉ: On a beaucoup parlé de ce qui explique les virages vers la gauche ou vers la droite en Amérique latine. Les études comparées des élections y sont nombreuses, quoique peu utiles pour expliquer les choix des électeurs le long du spectre idéologique, dont elles n'examinent que des causes isolées. Notre étude, consacrée au vote idéologique des Latinoaméricains entre 1996 et 2016, met en évidence que les deux facteurs déterminants les plus importants sont l'attitude envers les États-Unis (pour ou contre) et l'idéologie des électeurs, même si d'autres éléments ont aussi du poids: la classe sociale, la confiance envers les institutions politiques, l'idéologie du gouvernement au pouvoir et le sexe de l'électeur. Le fait d'appartenir à la population autochtone favorise le vote pour la gauche au cas où l'ethnicité serait préalablement politisée. Il y a pourtant des variations nationales importantes par rapport aux tendances régionales, ce qui prouve que l'ensemble des pays est très hétérogène.

Mots clefs: Amérique latine, vote idéologique, comportement électoral, gauche, droite.

\section{Traducción de Bernardo Mabire}

Fecha de recepción: junio de 2018

Fecha de aceptación: agosto de 2019 


\section{INTRODUCCIÓN}

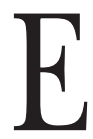

n los últimos quince años, la literatura académica comparada sobre América Latina y el periodismo han resaltado la presencia de dos procesos políticos que se habrían producido en la mayoría de los países de la región: un giro a la izquierda (entre 1998 y 2014, aproximadamente) y un retorno a la derecha (a partir de 2015). El primero ha sido ampliamente estudiado por especialistas, aunque aún quedan muchas interrogantes sin respuesta, y el segundo recién empieza a analizarse, por lo que de momento dominan las notas periodísticas y los estudios de caso sobre los estudios comparados de índole científica. No obstante, es importante mencionar de inicio que una debilidad de las aproximaciones a ambos giros radica en estudiarlos de forma aislada, es decir, como si fueran casos desvinculados de un proceso político continuo más amplio, a saber, la competencia política en democracias que aún presentan muchos déficits. Ello impide entender qué factores orientan a los latinoamericanos a votar por las alternativas de izquierda o de derecha (lo que denominaremos voto ideológico). ${ }^{1}$

El giro a la izquierda es incontestable. Comenzó en Venezuela con la victoria de Hugo Chávez, en 1998, y se propagó con tanto éxito que, a fines de la década pasada, aproximadamente dos tercios de la población latinoamericana estaba gobernada por presidentes que suscribían esa corriente política. Ese giro fue heterogéneo en varios sentidos, por ejemplo, en unos países duró varios periodos de gobierno y en otros sólo uno; en algunos casos hubo renovación en el liderazgo de izquierda y en otros derivó en el caudillismo; en algunos el gobierno promovió cambios institucionales pro-

${ }^{1}$ Si bien la dimensión izquierda-derecha no es la única para clasificar las posiciones políticas, sí es la más conocida en el debate político y la que más se usa como criterio de referencia y diferenciación, tanto entre candidatos como entre votantes. 
fundos y en los demás se mantuvo la estructura institucional previa, pero lo que une todas esas experiencias es su esfuerzo deliberado por reducir el rezago social y la desigualdad económica. Sólo cuatro de los dieciocho países de la región (México, Colombia, Honduras y República Dominicana) no fueron parte de ese giro, lo que explica en buena medida por qué recibió tanta atención.

La existencia de un giro de retorno a la derecha aún se discute $y$, aunque cada vez queda más claro que el giro a la izquierda ha finalizado, ${ }^{2}$ todavía no se observa que el péndulo electoral latinoamericano se ubique en forma predominante a la derecha del espectro político; es más, actualmente la identificación ideológica de los gobernantes en la región es más bien mixta. Sin embargo, no hay duda de que los partidos y candidatos de derecha han tenido en fechas recientes un éxito creciente en la conquista del poder. Este proceso llamó la atención del periodismo con el triunfo electoral de Mauricio Macri en Argentina, a fines de 2015, la victoria legislativa que obtuvo la oposición a Maduro ese mismo año en Venezuela, y la destitución de Dilma Rousseff en 2016 y el reciente triunfo de Jair Bolsonaro en Brasil. ${ }^{3} \mathrm{El}$ avance de la derecha ha ocasionado en algunos países fuertes tensiones debido a la poca o nula disposición de los gobernantes de izquierda de ceder siquiera parcialmente su poder (o ante las perspectivas futuras de una derrota electoral). Ese com-

${ }^{2}$ A fines de 2018, la izquierda gobierna en siete de dieciocho países latinoamericanos, lo que significa que su presencia ya no es dominante, aunque sigue siendo importante. De los cinco países más poblados, sólo gobierna en México.

${ }^{3}$ Véase, por ejemplo, Gerardo Lissandry, "Por qué 2017 puede ser clave en el giro hacia la derecha de América Latina”, BBC Mundo, 5 de enero de 2017, http://www.bbc.com/mundo/noticias-america-latina-38493148 y Ernesto Londoño, Pascal Bonnefoy y Daniel Politi, "La victoria de Piñera refuerza el giro a la derecha en América Latina”, The New York Times, 17 de diciembre de 2017, https:/ /www.nytimes.com/es/2017/12/19/chile-pinera-america-latina-derecha/ 
portamiento ha sido visible en Bolivia, Nicaragua y, en mayor escala, en Venezuela.

Más allá de conocer las características del giro a la izquierda o de retorno a la derecha (lo que implica analizar el comportamiento de los actores políticos más importantes, los cambios impulsados, el contexto externo y económico prevalecientes, etc.), es poco lo que se sabe sobre el voto de las personas que ocasionó estos cambios. Si bien hay una amplia reflexión intelectual en torno a las causas de ambos, existen muy pocos estudios que busquen evidencia para conocer qué factores influyen en que las personas voten por candidatos de uno u otro lado del espectro ideológico. Por ello, hemos decidido analizar el comportamiento electoral de los latinoamericanos entre 1996 y 2016. Es decir, consideramos que el surgimiento de estos giros es producto de la forma en que los individuos votan, y es eso lo que debe explicarse. Por esta razón, nuestro trabajo no aísla cada uno de esos procesos para estudiarlo por separado. Creemos que esa aproximación no ayuda a identificar los factores más relevantes que influyen en que las personas voten por candidatos de izquierda o de derecha en la región. Éste es el objetivo del presente trabajo. Además, se examinará en qué medida los países se ajustan o alejan de la tendencia regional, lo que es relevante dado que América Latina es más heterogénea de lo que suele asumirse en los análisis comparados.

\section{EXPLICACIONES SOBRE EL COMPORTAMIENTO ELECTORAL Y LOS GIROS EN AMÉRICA LATINA}

En los estudios sobre comportamiento electoral destacan tres enfoques teóricos: ${ }^{4}$ el sociológico (identificado con la

${ }^{4}$ Buenas descripciones sobre la evolución de esos enfoques se encuentran en Rui Antunes, "Theoretical models of voting behaviour", Exedra, núm. 4 (2010), pp. 145-170 y Larry M. Bartels, "The Study of Electoral Behavior", en Jan E. Leighley (ed.), The Oxford Handbook of American Elections and Political Behavior. Oxford, University Press, 2010, pp. 239-260. 
Universidad de Columbia), el psicológico (relacionado con la Universidad de Michigan) y el de la elección racional.

El primero destaca la importancia que tienen las características sociales del individuo sobre su decisión de por quién votar, siendo el nivel socioeconómico, la religión y el origen étnico de las personas las variables que mejor explican el sentido del voto. ${ }^{5}$ En el segundo, la identificación partidista, entendida como vínculo psicológico entre el votante y un partido político, que se adquiere a través del proceso de socialización, es la que más influye en la alternativa electoral escogida, ${ }^{6}$ en tanto que, en el tercer enfoque, es la evaluación retrospectiva sobre el desempeño de los gobernantes que efectúa cada persona la causa de que se vote por uno u otro candidato. ${ }^{7}$ Estas explicaciones no son irreconciliables y hay evidencia que respalda sus planteamientos, en especial en Estados Unidos y en Europa occidental, lo que muestra que lo social, lo psicológico y lo racional forman parte de los seres humanos. Por ello, no hay motivos a priori para excluir alguno de esos enfoques en este trabajo, de modo que se incluirán solamente en función de la pertinencia que tengan para el análisis del voto ideológico de los latinoamericanos.

Los análisis comparados sobre el voto en América Latina se multiplicaron a partir del giro a la izquierda, con el propósito de explicar por qué la gente decidió en muchos países, y en un periodo relativamente breve, votar mayoritariamente por can-

${ }^{5}$ Véase Bernard R. Berelson, Paul F. Lazarsfeld y William N. McPhee, Voting: A Study of Opinion Formation in a Presidential Campaign, Chicago, University of Chicago Press, 1954.

${ }^{6}$ Véase Agnus Campbell et al., The American Voter, Nueva York, John Wiley \& Sons, 1960; Fernanda Somuano y Reynaldo Ortega, "La identificación partidista de los mexicanos y el cambio electoral, 1994-2000", Foro Internacional, vol. 43, núm. 1 (2003), pp. 10-38, y John Bartle y Paolo Bellucci, "Introduction. Partisanship, social identity and individual attitudes", en John Bartle y Paolo Bellucci (eds.), Political parties and partisanship, Londres, Routledge, 2009.

${ }^{7}$ Véase Morris P. Fiorina, Retrospective Voting in American National Elections, New Haven, Yale University Press, 1981. 
didatos que cuestionaban las políticas de mercado puestas en marcha por los gobernantes anteriores. ${ }^{8}$ Las principales causas identificadas son la crisis económica que experimentó la región entre 1998 y 2002, y el descontento democrático que imperaba en las personas en esos años. También se menciona, aunque con menos frecuencia, que la institucionalización de la competencia política a través de la organización periódica de elecciones permitió que las izquierdas, que habían estado debilitadas durante más de una década, accedieran a la presidencia, y eso fue posible en virtud de que éstas habían ganado previamente espacios de poder subnacional de manera gradual. A continuación, desarrollaremos los argumentos de la literatura al respecto.

La década de los años noventa en América Latina se caracterizó por la puesta en marcha de reformas económicas que buscaban disminuir las restricciones y distorsiones de mercado, lo que, según los señalamientos de esa época, ${ }^{9}$ haría posible alcanzar altos niveles de crecimiento y reducir la pobreza. ${ }^{10} \mathrm{Si}$ bien el impulso a esas reformas fue muy heterogéneo (Chile y Bolivia fueron los casos más avanzados, y en Uruguay se reformó menos), ${ }^{11}$ no puede negarse que hubo

${ }^{8}$ La izquierda latinoamericana es muy heterogénea, pero una característica que tiene en común es su búsqueda por la disminución de la desigualdad socioeconómica y su disposición a hacer uso del Estado para ello. Para profundizar en esa discusión véase Mario Torrico (ed.), ¿̇Fin del giro a la izquierda en América Latina?, México, Flacso, 2017.

${ }^{9}$ Véase Bela Balassa et al., Hacia una renovación del crecimiento en América Latina. Washington: Institute for International Economics, 1986.

${ }^{10}$ Las políticas más importantes que debían impulsarse fueron resumidas por John Williamson, "What Washington Means by Policy Reform", en John Williamson, Latin American. How much has happened?, Washington DC, Institute for International Economics, 1990, en cuyo texto apareció una frase que se hizo célebre: "el consenso de Washington". Sin embargo, esas políticas ya estaban siendo adoptadas varios años antes en la mayoría de los países de la región.

${ }^{11}$ Véase Eduardo Lora, "Las reformas estructurales en América Latina: Qué se ha reformado y cómo medirlo", Documento de trabajo del BID \# IDB-WP-346, 2012. 
un esfuerzo importante de los gobiernos por establecer economías de mercado en las que el Estado tuviera menor injerencia en comparación con el pasado. En poco tiempo, las economías volvieron a mostrar crecimiento positivo (en contraste con la profunda crisis de los años anteriores), ${ }^{12}$ lo que reforzó la idea de que el camino trazado por el nuevo modelo (conocido como neoliberalismo) era irreversible. Sin embargo, entre 1998 y 2002 la mayoría de los países atravesó por otro periodo de crisis de sus economías que, aunque de menor escala que la de los ochenta, fue suficiente para encender el descontento social, el cual derivó en crisis política en varios casos. ${ }^{13}$ Para algunos autores esa situación reveló el desencanto social con los resultados obtenidos luego de varios años de reformas estructurales ${ }^{14}$ y para otros evidenció

12 En la década de los ochenta el crecimiento promedio latinoamericano fue de 1.29 por ciento; en cambio, entre 1990 y 1995, se creció 4.08 por ciento en promedio.

${ }^{13}$ Que provocaron la salida anticipada forzada de varios presidentes en un contexto de masivas protestas populares (De la Rúa en Argentina, Sánchez de Lozada en Bolivia, Mahuad en Ecuador).

${ }^{14}$ Jorge Lanzaro, "La 'tercera ola' de las izquierdas latinoamericanas: entre el populismo y la social-democracia”, Estudio/Working Paper, núm. 91, Uruguay, Universidad de la República, 2008; Ludolfo Paramio, "La izquierda en América Latina", Quórum, Revista de pensamiento iberoamericano, núm. 22 (2008), pp. 21-29; Philip Oxhorn, "Beyond Neoliberalism? Latin America's New Crossroads", en John Burdick; Philip Oxhorn y Kenneth M. Roberts (eds.), Beyond Neoliberalism in Latin America? Societies and Politics at the Crossroads, Nueva York, Palgrave, 2009; Francisco Panizza, "Nuevas izquierdas y democracia en América Latina", Revista CIDOB d'Afers Internacionals, núm. 85/86 (2009), pp. 75-88; Sebastián Santander, "El 'giro a la izquierda' en América Latina: Fragmentación y recomposición de la geopolítica regional", Cuadernos sobre Relaciones Internacionales, Regionalismo y Desarrollo, vol. 4, núm. 7 (2009), pp. 17-38; Jon Beasley-Murray; Maxwell A. Cameron y Eric Hershberg, "Latin America's Left Turns: A Tour D'Horizon", en Maxwell A. Cameron y Eric Hershberg (eds.), Latin America's Left Turns: Politics, Policies, and Trajectories of Change, Boulder, Lynne Rienner, 2010; Juan Pablo Luna, "The Left Turns: Why They Happened and How They Compare", en Maxwell A. Cameron y Eric Hershberg (eds.), Latin America's Left Turns: Politics, Policies, and Trajectories of Change, Boulder, Lynne Rienner, 2010; Steven Levitsky y Kenneth M. 
el fracaso del neoliberalismo; ${ }^{15}$ en cualquier caso, ambas interpretaciones coinciden en que el giro a la izquierda en la región fue causado por ese periodo de crisis económica, denominado "media década perdida" por la CEPAL. ${ }^{16}$

El descontento social mencionado no sólo fue provocado por la mala situación de la economía, sino también por el mal desempeño de los representantes políticos. Según datos de Latinobarómetro, entre 1998 y 2002, más del 60 por ciento de los encuestados estaba insatisfecho con el funcionamiento de la democracia, a pesar de que el apoyo a ésta, por encima de cualquier autoritarismo, era mayoritario. Los partidos y los congresos nacionales eran particularmente mal vistos porque la confianza en ellos era muy baja ( 17 y 23 por ciento en promedio, respectivamente) y alrededor de dos tercios de las personas creía que ambos eran prescindibles para las democracias. Además, 86 por ciento, en promedio, de la gente consideraba que la corrupción había aumentado

Roberts, "Introduction: Latin America's 'Left Turn'. A framework for analysis”, en Steven Levitsky y Kenneth M. Roberts (eds.), The Resurgence of the Latin American Left, Baltimore, The Johns Hopkins University Press, 2011; Kurt Weyland, "The Performance of Leftist Governments in Latin America: Conceptual and Theoretical Issues”, en Kurt Weyland; Raúl L. Madrid y Wendy Hunter (eds.), Leftist Governments in Latin America. Successes and Shortcomingst, Cambridge, University Press, 2010.

15 Ernesto Laclau, "La deriva populista y la centroizquierda latinoamericana”, Nueva Sociedad, núm. 205 (2006), pp. 56-61; Benjamín Arditi, "El giro a la izquierda en América Latina: ¿una política post-liberal?", Ciências Sociais Unisinos, vol. 45, núm. 3 (2010), pp. 232-246; Laura Macdonald y Arne Ruckert, "Post-Neoliberalism in the Americas: An Introduction”, en Laura Macdonald y Arne Ruckert (eds.), Post-Neoliberalism in the Americas, Nueva York, Palgrave, 2009; Emir Sader, El Nuevo Topo. Los caminos de la izquierda latinoamericana, Buenos Aires, Siglo XXI/CLAcso, 2009; Atilio Borón, “¿Una nueva era populista en América Latina?”, en Martha Lucía Márquez, Eduardo Pastrana y Guillermo Hoyos (eds.), El Eterno Retorno del Populismo en América Latina y el Caribe, Bogotá, Pontificia Universidad Javeriana/cLAcso, 2012.

16 Comisión Ecónomica para América Latina (CEPAL), Estudio Económico de América Latina y el Caribe 2001-2002, CEPAL, Santiago de Chile, 2002. 
en sus países. Esas cifras muestran que en la región existía una crisis de representación, ${ }^{17}$ la cual ha sido señalada como otra de las causas de que los votantes decidan apoyar a candidatos de izquierda, varios de los cuales no sólo criticaban el modelo económico neoliberal, sino también los patrones de comportamiento de los principales actores del sistema político, caracterizados por la corrupción y el clientelismo. ${ }^{18}$

La crisis económica de 1998-2002 y la crisis de representación política son, por mucho, las causas del giro a la izquierda más mencionadas en la literatura. Adicionalmente, se señalan dos factores que habrían facilitado que las izquierdas llegaran a la presidencia: la institucionalización de la competencia política y el avance gradual que éstas tuvieron en el ámbito subnacional. Para comprender su importancia, debe tomarse en cuenta que las fuerzas de izquierda se encontraban muy debilitadas en la década de los noventa en la que, de acuerdo con datos de Baker y Greene, ${ }^{19}$ ningún candidato de izquierda llegó a ser presidente en algún país de la

${ }^{17}$ Que en ese momento había sido identificada por un informe del Programa de las Naciones Unidas para el Desarrollo (PNUD) (La democracia en América Latina. Hacia una democracia de ciudadanas y ciudadanos. El debate conceptual sobre la democracia, Buenos Aires, Alfaguara, 2004), que tuvo amplia difusión regional.

${ }^{18}$ Jorge Lanzaro, "Gobiernos de izquierda en América Latina: entre el populismo y la socialdemocracia”, en Ernst Hillebrand (ed.), La izquierda en América Latina y Europa: nuevos procesos, nuevos dilemas, Uruguay, Friedrich Ebert Stiftung, 2007; Paramio, art. cit.; Maxwell Cameron, "Latin America's Left Turns: beyond good and bad", Third World Quarterly, vol. 30, núm. 2 (2009), pp. 331-348; Panizza, art. cit.; Santander, art. cit.; Eduardo Silva, Challenging Neoliberalism in Latin America, Cambridge, Cambridge University Press, 2009; Luna, op. cit.; Mabel Thwaites Rey, "Después de la globalización neoliberal: ¿qué Estado en América Latina?", Observatorio Social de América Latina, año XI, núm. 27 (2010), pp. 19-43.

${ }^{19}$ Baker y Greene (Andy Baker y Kenneth F. Greene, "The Latin American Left's Mandate: Free-Market Policies and Issue Voting in New Democracies", World Politics, vol. 63, núm. 1 (2011), pp. 43-77) miden la ideología de los partidos en toda América Latina en una escala que va de 1 (extrema izquierda) a 20 (extrema derecha) con base en encuestas a expertos de cada país. 
región. Esto tiene sentido si se toma en cuenta que en 1998, según Latinobarómetro, 77 por ciento de los encuestados señalaba que la economía de mercado era lo más conveniente para su país y 51 por ciento estaba de acuerdo con que las privatizaciones de empresas estatales había sido beneficiosa (en 2002, esas cifras fueron siete y veinte puntos porcentuales menores, respectivamente). Es decir, en esa década, los planteamientos que suelen caracterizar a posiciones de izquierda (como la participación del Estado en la economía, ya sea con un papel de productor, regulador o redistribuidor) tenían poco apoyo. El consenso sobre los beneficios de las reformas económicas de mercado fue tan grande, que varios presidentes que pertenecían a partidos de tradición nacionalista-revolucionaria impulsaron la mayoría de las políticas recomendadas por el Consenso de Washington (por ejemplo, Carlos Menem, en Argentina; Carlos Salinas, en México, y Gonzalo Sánchez de Lozada, en Bolivia).

Las izquierdas pudieron reorganizarse en la medida en que las elecciones se convirtieron en la vía normal de acceso al poder. Esta institucionalización de la competencia política habría hecho posible que la gente castigue a los gobernantes pasados cuando las condiciones se vuelven difíciles, dando como resultado el giro a la izquierda. ${ }^{20}$ Incluso se llega a plantear que tal giro sólo se trataría de una alternancia política, ya que el electorado latinoamericano no habría experimentado cambios ideológicos y es predominantemente de centro. ${ }^{21}$ El proceso de normalización electoral también se produjo a nivel subnacional, donde las izquierdas lograron importantes avances antes de ganar la presidencia y varios de sus líderes llegaron a gobernar ciudades importantes, como Caracas, Brasilia, São Paolo, Montevideo, San Salvador y la

20 Castañeda, 2006; Clearey, 2006; Steven Levitsky y Kenneth M. Roberts, "Introduction: Latin America's 'Left Turn'. A framework for analysis", en Steven Levitsky y Kenneth M. Roberts (eds.), The Resurgence of the Latin American Left, Baltimore, The Johns Hopkins University Press, 2011.

21 Panizza, art. cit. 
Ciudad de México. Para Panizza y Levitsky y Roberts, ${ }^{22}$ eso permitió que el temor de varios sectores del electorado hacia éstas disminuyera, en especial en aquellos lugares en que tuvieron una gestión pública exitosa, lo que se sumó a la experiencia que fueron ganando en el juego de compromisos y alianzas políticas, en virtud del acceso que tuvieron a los congresos nacionales de los países. Todo ello habría proyectado una imagen distinta sobre la izquierda a la que tradicionalmente imperaba y que la asociaba con movimientos guerrilleros y disposición a la violencia. En consecuencia, su atractivo electoral aumentó.

Las explicaciones anteriores sobre el porqué los latinoamericanos decidieron votar por candidatos de izquierda, dando lugar al correspondiente giro, pertenecen al ámbito interno de los países. En relación con el contexto externo, suele destacarse dos causas: la mala imagen de Estados Unidos en la región ${ }^{23}$ y el surgimiento de un proceso de difusión regional hacia la izquierda, similar a un efecto contagio, de un país a otro. ${ }^{24} \mathrm{El}$ antiamericanismo suele asociarse con el voto a la izquierda debido a que las reformas económicas de mercado contaron con el beneplácito y el estímulo de los gobernantes de ese país, y a que en el pasado muchos gobiernos de derecha fueron cercanos a Washington y reprimieron movimientos y grupos opositores. ${ }^{25} \mathrm{Al}$ respecto, Arnold y

22 Panizza, art. cit. y Levitsky y Roberts, op. cit.

23 Baker y Greene, art. cit.; Karen Remmer, "The Rise of Leftist-Populist Governance in Latin America: The Roots of Electoral Change”, Comparative Political Studies, vol. 45, núm. 8 (2012), pp. 947-972.

${ }^{24}$ Levitsky y Roberts, op. cit.

25 Otro planteamiento sobre la influencia de Estados Unidos en el giro a la izquierda es el que señala que luego del ataque a las Torres Gemelas, en 2001, y especialmente después de la IV Cumbre de las Américas de 2005 en Mar del Plata, en la que naufragó el proyecto de constituir un área de libre comercio continental (ALCA), el gobierno de ese país decidió concentrar sus esfuerzos internacionales en las invasiones de Irak, Afganistán y en los conflictos posteriores en Medio Oriente, lo que permitió que emergiera con fuerza la izquierda regional sin enfrentar la oposición americana (Cameron, 2009). Este señalamiento no se toma en cuenta en el 
Samuels ${ }^{26}$ aportan evidencia de que la simpatía por la izquierda está asociada con un sentimiento antiestadounidense. La difusión regional tiene que ver con el buen desempeño que tuvieron los primeros gobiernos de izquierda, que redujo los temores que podían tener algunos sectores de la población en otras naciones hacia los candidatos de esa corriente ideológica e hizo posible que ese giro se extendiera en más países.

A pesar de que existe una gran cantidad de trabajos que analizan por qué los latinoamericanos votaron por candidatos de izquierda, ocasionando el giro correspondiente, son pocos los que someten a prueba empírica los principales planteamientos que hacen o que se hicieron al respecto y, en general, abundan los textos de estilo ensayístico. Entre los pocos que buscan evidencia, algunos recurren a datos agregados o de tipo macro, que no pueden dar cuenta de la conexión entre el voto de las personas y los procesos políticos de los países. ${ }^{27}$ En consecuencia, son muy escasos los autores cuyos hallazgos pueden reportarse ( $\mathrm{y}$, más adelante, contrastar con los nuestros). Así, Remmer ${ }^{28}$ encuentra que el voto por la izquierda aumenta cuando la gente evalúa su situación económica como buena, cuando manifiesta que está satisfecha con la democracia (contrario a lo esperado por la literatura) y cuando tiene una imagen negativa de Estados Unidos; Queirolo, ${ }^{29}$ que estudia los casos de Brasil, México y Uruguay, halla que la ideología de las per-

presente trabajo debido a que es independiente de las preferencias individuales de las personas que votan en elecciones.

26 Jason R. Arnold y David J. Samuels, "Evidence from public opinion”, en Steven Levitsky y Kenneth M. Roberts (eds.), The Resurgence of the Latin American Left, Baltimore, The Johns Hopkins University Press, 2011.

${ }^{27}$ Por ejemplo, Baker y Greene, art. cit.; Luisa Blanco y Robin Grier, "Explaining the Rise of the Left in Latin America", Latin American Research Review, vol. 48, núm. 1 (2013), pp. 68-90; Nina Wiesehomeier y David Doyle, "Discontent and the Left Turn in Latin America", Political Science Research and Methods, vol. 1, núm. 2 (2013), pp. 201-221.

28 Remmer, art. cit.

29 Rosario Queirolo, The Success of the Left in Latin America, Notre Dame, University of Notre Dame Press, 2013. 
sonas es un determinante significativo del voto, que la gente tiende a votar por la izquierda cuando percibe que la situación económica propia y la del país es mala (lo opuesto de Remmer), y que, en general, no hay relación entre el sentido del voto y la clase social de los individuos; y Dosek, ${ }^{30}$ que analiza lo sucedido en Bolivia y Uruguay, concluye que la ideología es un buen predictor del voto, que la evaluación retrospectiva favorable de la economía incrementa el voto de los candidatos de izquierda (en los años estudiados el oficialismo era de izquierda en ambos países) y que, en el caso boliviano, los indígenas tienden a votar por Evo Morales. Las diferencias en los hallazgos de los mencionados autores se deben principalmente a los casos escogidos y al periodo analizado, pero resultan de utilidad para poner en perspectiva nuestros resultados.

El análisis del giro a la derecha se encuentra aún en una etapa inicial, ${ }^{31}$ pero los textos que lo abordan señalan como causas principales los mismos factores que son más mencionados en la literatura del giro a la izquierda: la reducción de precios de materias primas que afectó el crecimiento de las economías ${ }^{32}$ y el descontento por los escándalos de co-

${ }^{30}$ Tomás Dosek, “¿Por qué la gente vota a la izquierda? Clivajes, ideología y voto retrospectivo en Bolivia y Uruguay en perspectiva comparada", DADOS-Revista de Ciências Sociais, vol. 57, núm. 3 (2014), pp. 773-815.

${ }^{31}$ Por ello, este recuento incluye notas que importantes medios de comunicación han publicado respecto a las causas de dicho giro.

32 Katu Arkonada, "¿Fin de ciclo? La disputa por el relato", América Latina en Movimiento, núm. 510 (2015), pp. 11-16; Massimo Modonesi, "Fin de la hegemonía progresista y giro regresivo en América Latina. Una contribución gramsciana al debate sobre el fin de ciclo", Viento Sur, núm. 15 (2015), pp. 23-30; Mohamed A.El-Erian, "El ascenso de la derecha en América Latina”, La Nación, 12 de junio de 2016, https:/ / goo.gl/2gHcXC; Daniel Matos y Eduardo Molina, "Giro a la derecha y lucha de clases en Sudamérica”, Estrategia Internacional, núm. 29 (2016), pp. 9-25; Londoño, et al., art, cit,; Constanza Moreira, "El largo ciclo del progresismo latinoamericano y su freno. Los cambios políticos en América Latina en la última década (2003-2015)", Revista Brasileira de Ciencias Sociais, vol. 32, núm. 93 (2017), pp. 1-28. 
rrupción en que se vieron envueltos varios gobiernos de izquierda. ${ }^{33}$ Adicionalmente, se señalan dos novedades que supuestamente favorecen a los candidatos de derecha: el aumento de la delincuencia (que genera una demanda de "mano dura" del gobierno en algunos sectores), y el avance de los evangélicos (y su agenda conservadora). ${ }^{34}$ Aunque el debate al respecto aún está a la espera de evidencia que permita extraer conclusiones, el hecho de que la incipiente literatura sobre el giro a la derecha coincida con los textos que analizaron el giro anterior, en que los principales factores que impulsaron los cambios en la orientación ideológica de los presidentes fueron la crisis de la economía y la insatisfacción con la forma en que están funcionando las instituciones políticas, obliga a ampliar la mirada sobre el voto ideológico en la región, algo que afortunadamente empieza a realizarse.

En los últimos años se observa un esfuerzo académico por entender al votante latinoamericano independientemente de las coyunturas de los giros a la izquierda o a la derecha (al respecto, se han escrito dos libros que llevan el mismo título, aunque uno en inglés y otro en español). ${ }^{35}$ Los aportes más importantes en lo que concierne al presente artículo son que se reconoce que la región no se caracteriza por la estabilidad e institucionalización de la mayoría de sus partidos, como es el caso de Estados Unidos y de Europa occidental -donde las

33 Arkonada, Loc. cit.; Matos y Molina, Loc. cit.; Gerardo Lissandry, "Por qué 2017 puede ser clave en el giro hacia la derecha de América Latina", BBC Mundo, 5 de enero de 2017, http:/ /www.bbc.com/mundo/ noticias-america-latina-38493148; Londoño, Loc. cit., 2017; Constanza Moreira, Loc. cit.

${ }^{34}$ Lissandry, Loc. cit.

35 "The Latin American Voter", de Ryan Carlin, Matthew M. Singer y Elizabeth J. Zechmeister, "Introduction to the Latin American Voter", en Ryan Carlin, Matthew M. Singer y Elizabeth J. Zechmeister (eds.), The Latin American Voter: Pursuing Representation and Accountability in Challenging Contexts, Ann Arbor, University of Michigan Press, 2015, y El Votante Latinoamericano, de Helcimara Telles y Alejandro Moreno (coords.), El votante latinoamericano. Comportamiento electoral y comunicación política, México, Cesop, 2015. 
teorías sobre el comportamiento electoral han encontrado evidencia de respaldo-, lo que se refleja en muy altos niveles de volatilidad y en, muchos casos, en cambios repentinos en la fragmentación partidista debido a que el surgimiento y la desaparición de partidos es constante. En consecuencia, la identificación partidista es más débil (o casi inexistente en algunas naciones), lo que da como resultado que los factores de corto plazo (como la evaluación de la economía) sean más relevantes para los electores. ${ }^{36}$ Respecto al voto ideológico, Mainwaring et al. ${ }^{37}$ encuentran evidencia de que en la mayoría de los países latinoamericanos existe actualmente un voto orientado por la clase social (las personas de menores ingresos votan por la izquierda) que no se observaba en la década de los noventa, Morgan ${ }^{38}$ llega a la conclusión de que las mujeres votan más por los candidatos de derecha y Moreno ${ }^{39}$ señala que la pertenencia indígena influye en el voto cuando las líneas étnicas o raciales han sido previamente politizadas (lo que solamente sucede en Bolivia, donde los indígenas votan masivamente por Evo Morales).

En la literatura especializada, el voto ideológico suele definirse como la decisión de votar por un partido con base en la identidad ideológica propia. ${ }^{40}$ Debido a que se ha mostra-

36 Telles y Moreno, op. cit.

37 Scott Mainwaring, "The Left and the Mobilization of Class Voting in Latin America”, en Ryan Carlin, Matthew M. Singer y Elizabeth J. Zechmeister (eds.), The Latin American Voter: Pursuing Representation and Accountability in Challenging Contexts, Ann Arbor, University of Michigan Press, 2015.

38 Jana Morgan, "Gender and the Latin American Voter", en Ryan Carlin, Matthew M. Singer y Elizabeth J. Zechmeister (eds.), The Latin American Voter: Pursuing Representation and Accountability in Challenging Contexts, Ann Arbor, University of Michigan Press, 2015.

${ }^{39}$ Daniel Moreno, "Ethnicity and Electoral Preferences in Latin America”, en Ryan Carlin, Matthew M. Singer y Elizabeth J. Zechmeister (eds.), The Latin American Voter: Pursuing Representation and Accountability in Challenging Contexts, Ann Arbor, University of Michigan Press, 2015.

40 Matthias Mader y Harald Schoen, "Ideological voting in context: The case of Germany during the Merkel era", en Harald Schoen et al. 
do en este apartado que el voto puede explicarse de muchas maneras y está influido por muchos factores, en el presente artículo se entenderá el voto ideológico simplemente como la decisión de votar por las opciones electorales de izquierda o de derecha (tómese en cuenta, además, que todos los trabajos lo miden utilizando una escala numérica que permite la ubicación en función de esa división) ${ }^{41}$ Esa definición mínima cumple con la condición de Burlacu ${ }^{42}$ de que, para que exista este tipo de voto, los votantes deben ser capaces de identificar las posiciones ideológicas de los partidos. La ventaja de la perspectiva adoptada es que permite observar el peso relativo de la ubicación ideológica propia en la explicación del voto y no sólo asumir que la ideología de los votantes se corresponde con su decisión electoral.

\section{MODELO DE ANÁLISIS Y SELECGIÓN DE VARIABLES}

En este trabajo se analizarán de forma agregada y desagregada los determinantes del voto ideológico en todos los países de América Latina ${ }^{43}$ en un periodo temporal que abarca no sólo los años de los giros a la izquierda y a la derecha. Por fortuna, Latinobarómetro nos proporciona información a lo largo de dos décadas (1996-2016), con la que puede estudiarse

(eds.), Voters and Voting in Context: Multiple Contexts and the Heterogeneous German Electorate, Oxford, University Press, 2016.

$41 \mathrm{Al}$ respecto, véase Romain Lachat "The impact of party polarization on ideological voting”, Electoral Studies, vol. 27, núm. 4 (2008), pp. 687-698; Henrik Oscarsson y Sören Holmberg, "Issue Voting Structured by Left-Right Ideology", en Jon Pierre (ed.), The Oxford Handbook of Swedish Politics, Reino Unido, Oxford University Press, 2015; Mader y Schoen, Loc. cit., y Diana Burlacu "Corruption and Ideological Voting", British Journal of Political Science, (2018), pp. 1-22. doi:10.1017/S0007123417000758.

42 Burlacu, Loc. cit.

43 Argentina, Bolivia, Brasil, Chile, Colombia, Costa Rica, Ecuador, El Salvador, Guatemala, Honduras, México, Nicaragua, Panamá, Paraguay, Perú, República Dominicana, Uruguay y Venezuela. No se incluye Cuba por inexistencia de datos. 
el vínculo entre las opiniones, percepciones y preferencias de las personas y los resultados políticos en los países. ${ }^{44} \mathrm{~A}$ la fecha, no conocemos un estudio sobre este tema que abarque toda la región durante tanto tiempo. La variable dependiente se obtiene a partir de la siguiente pregunta que se formula en todas las rondas de esa encuesta: "Si este domingo hubiera elecciones, ¿por qué partido votaría usted?”. Las respuestas de todos los encuestados fueron recodificadas utilizando la medición ideológica de partidos en la escala izquierda-derecha de Baker y Greene ${ }^{45}$ quienes, con base en encuestas a expertos, asignan valores entre 1 (extrema izquierda) y 20 (extrema derecha).

Nuestra explicación del voto ideológico toma en cuenta los aportes teóricos revisados en el apartado anterior. Así, se incluirán factores explicativos propios de los enfoques sociológico y de la elección racional sobre el comportamiento electoral. ${ }^{46}$ Se excluye el enfoque psicológico debido a que el estudio de la identificación partidista requiere una precondición en los países: la existencia sostenida y prolongada de los principales partidos políticos. En muchos casos de la región, no existen sistemas de partidos medianamente estables e institucionalizados y, por tanto, no es posible pensar que los votantes desarrollan vínculos partidistas de esta índole. Perú, Ecuador, Guatemala y Bolivia son algunos ejemplos en los que, en dos elecciones nacionales consecutivas, la mayoría de los partidos que se presentan son diferentes, situación que, además, se ha extendido durante más de una década. A ello se agrega que en Costa Rica, Honduras y Colombia, donde

${ }^{44}$ Se excluye del análisis la encuesta realizada en 1995 debido a que sólo abarcó ocho naciones.

${ }^{45}$ Baker y Greene, art. cit., cuyos datos están actualizados hasta 2016 y pueden consultarse en http://spot.colorado.edu/ bakerab/data.html

${ }^{46}$ Sin embargo, no estaremos en condiciones de afirmar si el voto de los latinoamericanos se apega a lo señalado por la escuela de elección racional, ya que esta construye sus planteamientos a partir de la distinción principal entre partidos oficialistas y opositores, donde la posición ideológica de los mismos se considera una categoría secundaria. 
tradicionalmente había sistemas de partidos institucionalizados, éstos se han transformado sustancialmente en los últimos años y han aparecido nuevas fuerzas con amplio apoyo electoral. Sin embargo, hay casos en que sí se observa esa precondición, como en Uruguay, República Dominicana, Chile y México. Ello revela que el supuesto de institucionalización del sistema de partidos del que parte el enfoque psicológico debe convertirse en una variable cuando se estudia América Latina. ${ }^{47}$ En consecuencia, si bien no incluiremos las categorías teóricas de la Escuela de Michigan, sí necesitamos saber en qué medida el grado de estabilidad y fragmentación del sistema de partidos afecta en la decisión electoral de las personas. ${ }^{48}$

Además de poner a prueba lo señalado en el párrafo anterior, en este trabajo se incluirán todos los factores explicativos identificados por la literatura del giro a la izquierda y

${ }^{47} \mathrm{Al}$ respecto, Scott Mainwaring y Mariano Torcal ("La institucionalización de los sistemas de partidos y la teoría del sistema partidista después de la tercera ola democratizadora", América Latina Hoy, núm. 41 (2005), pp. 141-173) señalan que los sistemas partidistas de las democracias de los países menos desarrollados, como los de América Latina, están marcadamente menos institucionalizados que los de las democracias industriales avanzadas, lo que se refleja en mayores niveles de volatilidad electoral. Mariano Torcal ([coord.], Sistema de partidos en América Latina. Causas y consecuencias de su equilibrio inestable, Barcelona, Anthropos, 2015) afirma que los partidos latinoamericanos aparecen y desaparecen con gran facilidad, generando una gran inestabilidad electoral. Por último, Mollie Cohen, Facundo E. Salles Kobilanski y Elizabeth J. Zechmeister, "Electoral Volatility in Latin America", The Journal of Politics, vol. 80, núm. 3 (2018, en línea), doi: 10.1086/697464, muestran que, de forma contraria a lo que sucede en Europa del Este y en África, la desinstitucionalización de los sistemas de partidos en América Latina se acentúa con el tiempo, lo que se muestra con la volatilidad electoral creciente.

${ }^{48} \mathrm{Si}$ bien se excluye la identificación partidista como variable explicativa del voto ideológico por motivos teóricos, de todas formas su inclusión hubiera sido imposible debido a que Latinobarómetro sólo la mide en cuatro rondas: 2010, 2011, 2013 y 2015. Incluirla habría significado sacrificar el grueso de los datos y perder la perspectiva de largo plazo que tiene este trabajo. 
del giro a la derecha, tanto los que tienen que ver con el ámbito interno de los países como los relacionados con el ámbito externo, a saber, la percepción sobre el estado de la economía, el grado de satisfacción con la democracia y sus instituciones, ${ }^{49}$ la institucionalización de la competencia política, ${ }^{50}$ la existencia de gobiernos subnacionales de izquierda, el antiamericanismo, la difusión regional hacia la izquierda, la ideología de los votantes, ${ }^{51}$ la delincuencia y la religión evangélica (nótese que algunos de ellos podrían incluirse en una explicación de elección racional). También se consideran los hallazgos de quienes estudian al "votante latinoamericano", por lo que la clase social y el género son factores a tomar en cuenta en la explicación del voto ideológico. La pertenencia indígena se examinará en un apartado específico que incluirá sólo los

${ }^{49}$ Recuérdese que ambos factores han sido destacados tanto por la literatura del giro a la izquierda como por la del giro a la derecha en América Latina, por lo que no podemos anticipar qué tipo de relación tienen con el voto ideológico. El resultado que se obtendrá podrá considerarse muy confiable en virtud de que en el análisis también se incluyen todos los demás factores explicativos posibles.

${ }^{50}$ Su inclusión permitirá saber si la evidencia brinda respaldo al planteamiento del apartado anterior respecto a que el giro a la izquierda fue posible en virtud de que en los países de América Latina las elecciones se convirtieron en la vía ordinaria de acceso al poder.

${ }^{51}$ La ideología de los votantes fue incluida por Queirolo, op. cit. y por Dosek, art.cit., como variable de control, pero en este trabajo será una de las variables independientes debido a su importancia según los hallazgos de esos autores. Aunque podría pensarse a priori que no es necesaria la inclusión de esta variable para explicar el voto ideológico por ser redundante (en el cuadro 1 se detalla su medición), su correlación con la variable dependiente sólo es de 0.31 en la región, observándose los valores más altos en Uruguay (0.7), Chile (0.56) y El Salvador (0.55). Salvo en el caso uruguayo, esos niveles de asociación están lejos de los que se observan en democracias muy institucionalizadas, como la sueca, con 0.77 para el periodo 1979-2010, según Oscarsson y Holmberg, op. cit.. Al respecto, Mainwaring y Torcal, art. cit., señalan que en democracias como las latinoamericanas las uniones programáticas e ideológicas entre los votantes y los partidos son más débiles de lo que supone la literatura clásica. 
casos de Bolivia, Guatemala, Paraguay y Perú. ${ }^{52}$ El análisis se efectuará con controles por la orientación ideológica del gobierno actual, el nivel de desigualdad y de desarrollo de los países, la edad y los años de estudio de los encuestados. A continuación se exponen los detalles relevantes de todas las variables seleccionadas.

\section{CuAdro 1}

Variables independientes del modelo de análisis

\begin{tabular}{|c|c|c|c|}
\hline Variable & $\begin{array}{l}\text { Enfoque teórico o } \\
\text { factor explicativo }\end{array}$ & Valores & Fuente \\
\hline $\begin{array}{l}\text { Situación } \\
\text { económica del } \\
\text { país }\end{array}$ & $\begin{array}{l}\text { Elección racional / } \\
\text { percepción sobre el } \\
\text { estado de la economía }\end{array}$ & $\begin{array}{l}1 \text { = Muy buena } \\
2 \text { = Buena } \\
3 \text { = Regular } \\
4=\text { Mala } \\
5=\text { Muy mala }\end{array}$ & Latinobarómetro \\
\hline $\begin{array}{l}\text { Crecimiento del } \\
\text { PIB en el año } \\
\text { anterior }\end{array}$ & Elección racional & En porcentaje & $\begin{array}{l}\text { World Development } \\
\text { Indicators }\end{array}$ \\
\hline $\begin{array}{l}\text { Satisfacción con } \\
\text { la democracia }\end{array}$ & $\begin{array}{l}\text { Grado de satisfacción } \\
\text { con la democracia y sus } \\
\text { instituciones }\end{array}$ & $\begin{array}{l}1=\text { Muy satisfecho } \\
2=\text { Más bien satisfecho } \\
3=\text { No muy satisfecho } \\
4=\text { Nada satisfecho }\end{array}$ & Latinobarómetro \\
\hline $\begin{array}{l}\text { Confianza en el } \\
\text { Congreso }\end{array}$ & $\begin{array}{l}\text { Grado de satisfacción } \\
\text { con la democracia y sus } \\
\text { instituciones }\end{array}$ & $\begin{array}{l}1=\text { Mucha } \\
2=\text { Algo } \\
3=\text { Poca } \\
4=\text { Ninguna }\end{array}$ & Latinobarómetro \\
\hline Polity & $\begin{array}{l}\text { Institucionalización de la } \\
\text { competencia política }\end{array}$ & De $-10 a+10$ & $\begin{array}{l}\text { Variable "polity2" de } \\
\text { Polity Project }{ }^{\mathrm{a}}\end{array}$ \\
\hline $\begin{array}{l}\text { Escala izquierda- } \\
\text { derecha }\end{array}$ & Ideología del votante & $\begin{array}{l}\text { De } 1 \text { (izquierda) a } 10 \\
\text { (derecha) }\end{array}$ & Latinobarómetro \\
\hline
\end{tabular}

${ }^{52}$ Esta decisión se debe al bajo porcentaje de encuestados por Latinobarómetro que pueden ser considerados indígenas (4 por ciento) y a que sólo es posible realizar este análisis a partir de 2002, con lo que se perderían cinco años de datos. En los países mencionados esa cifra es de 23, 12, 29 y 8 por ciento, respectivamente, las más altas de la región. 


\section{Cuadro 1 (continúa) Variables independientes del modelo de análisis}

\begin{tabular}{|c|c|c|c|}
\hline $\begin{array}{l}\text { Opinión sobre } \\
\text { EE.UU. }\end{array}$ & Anti Estados Unidos & $\begin{array}{l}0=\text { Regular, Mala, Muy } \\
\text { mala } \\
1 \text { = Buena, Muy buena }\end{array}$ & Latinobarómetro \\
\hline $\begin{array}{l}\text { Difusión } \\
\text { izquierda }\end{array}$ & $\begin{array}{l}\text { Difusión regional de la } \\
\text { izquierda }\end{array}$ & $\begin{array}{l}0=1996-2002 \\
1=2003-2016\end{array}$ & $\begin{array}{l}\text { En función del } \\
\text { primer triunfo de } \\
\text { Lula Da Silva }\end{array}$ \\
\hline $\begin{array}{l}\text { Gobiernos } \\
\text { subnacionales de } \\
\text { izquierdac }\end{array}$ & $\begin{array}{l}\text { Gobiernos subnacionales } \\
\text { de izquierda }\end{array}$ & $\begin{array}{l}0=\text { los partidos } \\
\text { de izquierda no } \\
\text { gobiernan a nivel } \\
\text { subnacional } \\
1 \text { = los partidos de } \\
\text { izquierda sí gobiernan } \\
\text { a nivel subnacional }\end{array}$ & $\begin{array}{l}\text { Datos oficiales de los } \\
\text { países }\end{array}$ \\
\hline Victimización & Delincuencia & $\begin{array}{l}0 \text { = No fue víctima de } \\
\text { delito } \\
1=\text { Sí fue víctima de } \\
\text { delito }\end{array}$ & $\begin{array}{l}\text { Latinobarómetro (no } \\
\text { cuenta con datos para } \\
2000)\end{array}$ \\
\hline Evangelismo & Religión evangélica & $\begin{array}{l}0=\text { No } \\
1=\mathrm{Si}^{\mathrm{d}}\end{array}$ & Latinobarómetro \\
\hline Auto & $\begin{array}{l}\text { Enfoque sociológico / } \\
\text { Clase social }\end{array}$ & $\begin{array}{l}0=\text { No tiene auto } \\
\text { propio } \\
1=\text { Sí tiene auto } \\
\text { propio }\end{array}$ & Latinobarómetro \\
\hline Sexo & Sexo del entrevistado & $\begin{array}{l}0=\text { Mujer } \\
1=\text { Hombre }\end{array}$ & Latinobarómetro \\
\hline $\begin{array}{l}\text { Volatilidad } \\
\text { electorale }^{\text {e }}\end{array}$ & $\begin{array}{l}\text { Institucionalización del } \\
\text { sistema de partidos }\end{array}$ & $\begin{array}{l}\text { Entre } 0 \text { y } 100 \text { (nula- } \\
\text { máxima volatilidad) }\end{array}$ & $\begin{array}{l}\text { Datos electorales ofi- } \\
\text { ciales de los países }\end{array}$ \\
\hline $\begin{array}{l}\text { Número efectivo } \\
\text { de partidos }{ }^{\mathrm{f}}\end{array}$ & $\begin{array}{l}\text { Fragmentación del } \\
\text { sistema de partidos }\end{array}$ & El valor mínimo es 1 & $\begin{array}{l}\text { Datos electorales ofi- } \\
\text { ciales de los países }\end{array}$ \\
\hline $\begin{array}{l}\text { Lengua materna } \\
\text { autóctona (sólo } \\
\text { para Bolivia, } \\
\text { Guatemala, } \\
\text { Paraguay y Perú) }\end{array}$ & $\begin{array}{l}\text { Enfoque sociológico / } \\
\text { pertenencia indígena }\end{array}$ & $\begin{array}{l}0=\text { Su lengua materna } \\
\text { no es autóctona } \\
1 \text { = Su lengua materna } \\
\text { sí es autóctona }\end{array}$ & Latinobarómetro \\
\hline
\end{tabular}




\section{CuAdro 1 (conclusión)}

Variables independientes del modelo de análisis

\begin{tabular}{|l|l|l|l|}
\hline $\begin{array}{l}\text { Ideología del } \\
\text { gobierno }\end{array}$ & $\begin{array}{l}\text { Orientación ideológica } \\
\text { del gobierno actual }\end{array}$ & $\begin{array}{l}0=\text { Derecha } \\
1=\text { Izquierda }\end{array}$ & $\begin{array}{l}\text { Mario Torrico, (ed.), } \\
\text { EFin del giro a la izquier- } \\
\text { da en América Latina?, } \\
\text { México, Flacso, 2017. }\end{array}$ \\
\hline Índice de Gini & Nivel de desigualdad & Entre 0 y 100 & $\begin{array}{l}\text { World Development } \\
\text { Indicators }\end{array}$ \\
\hline $\begin{array}{l}\text { PIB per cápita en } \\
\text { el año anterior }\end{array}$ & Nivel de desarrollo & $\begin{array}{l}\text { En miles de dólares a } \\
\text { precios constantes de } \\
\text { 2011, ppP }\end{array}$ & $\begin{array}{l}\text { World Development } \\
\text { Indicators }\end{array}$ \\
\hline Edad & & Conteo de años & Latinobarómetro \\
\hline Años de estudio & & Conteo de años & Latinobarómetro \\
\hline
\end{tabular}

Fuente: elaboración propia.

a Mide el nivel de democracia de los países. Sus valores van de -10 (máximo autoritarismo) a +10 (máxima democracia), Monty G. Marshall y Ted Robert Gurr, Polity IV Project. Political Regime Characteristics and Transitions, 1800-2015. Dataset, Maryland, Centre for Systemic Peace, 2016.

b Se toma como referencia el año del primer triunfo electoral de Lula Da Silva en Brasil, porque a partir de entonces se empezó a hablar de que América Latina comenzaba a girar a la izquierda, Panizza, art. cit.; Ludolfo Paramio, "Giro a la izquierda y regreso del populismo", Nueva Sociedad, núm. 205 (2006), pp. 62-74.

c Sólo se consideran los niveles de gobierno inmediatamente inferiores al nacional o federal (por ejemplo, estados en México, provincias en Argentina, departamentos en Colombia).

${ }^{\mathrm{d}}$ Incluye bautistas, metodistas, pentecostales, adventistas, testigos de Jehová, mormones, protestantes y cristianos evangélicos.

e Se mide utilizando el índice de Pedersen (1979): $\mathrm{V}=\Sigma\left|\mathrm{Pi}_{\mathrm{t}-1}-\mathrm{Pi}_{\mathrm{t}}\right| / 2$, donde $\mathrm{Pi}_{\mathrm{t}}$ es el porcentaje de votos del partido $i$ en la elección del año $t$, y $\mathrm{Pi}_{\mathrm{t}-1}$ es el porcentaje de votos del mismo partido en la elección previa.

${ }^{\mathrm{f}} \mathrm{Se}$ mide con el indicador elaborado por Markku Laakso y Rein Taagepera ("Effective Number of Parties: A Measure with Application to West Europe”, Comparative Political Studies, vol.12, núm. 1, 1979, pp. 3-27): $\mathrm{NEP}=1 / \Sigma \mathrm{pi}^{2}$, donde $\mathrm{pi}^{2}$ es el cuadrado de la proporción de votos recibida por cada partido.

Debido a que la variable dependiente es continua y a que se construyó una base de datos tipo panel por países, que incluye variables medidas tanto a nivel individual como agregado 
(estas últimas son las que no provienen de Latinobarómetro), para el análisis inferencial de toda América Latina, se empleará un modelo de regresión multinivel mixto con errores estándar robustos. ${ }^{53}$ Para el análisis de las relaciones entre

${ }^{53}$ Los modelos multinivel son utilizados cuando se cuenta con una estructura jerárquica en los datos, es decir, existen dos niveles en los que la información está agregada. En este trabajo contamos con información a nivel individual y de país. En este sentido, consideramos que los miembros de un mismo país están influidos por variables grupales (pertenecer al mismo país). Para este tipo de datos, el modelo de "mínimos cuadrados" es inadecuado porque viola el supuesto de independencia de las observaciones. Al utilizar un modelo multinivel podemos estimar a su vez el efecto que tienen las variables individuales y grupales sobre el voto ideológico. Marcel Lubbers y Take Sipma ("Multi-level Modelling of Voting Behaviour", en Kai Arzheimer; Jocelyn Evans y Michael S. Lewis-Beck (eds)., The Sage Handbook of Electoral Behaviour, Londres, Sage, 2017, pp. 934-951) consideran que el uso de este modelo permite modelar la influencia del contexto sobre los individuos y cómo el comportamiento de los individuos varía a través de distintos contextos. Esto es útil para analizar el comportamiento electoral, ya que la literatura identifica condiciones macro que afectan las actitudes, creencias e intención de voto de las personas. Este modelo está compuesto de un componente de efectos fijos, pertinente para todos los votantes latinoamericanos y que al mismo tiempo estima un componente de efectos aleatorios que permite que los interceptos y coeficientes varíen de país a país. El modelo multinivel utiliza el método de máxima similitud que conlleva el supuesto de que el tamaño de la muestra es grande. Este modelo puede presentar un problema si la muestra es relativamente pequeña, lo que tiene especial importancia para el nivel de agregación más alto, que por definición es más pequeño que la muestra del nivel más bajo. En este caso tenemos menos países que personas. De esto se sigue algo que ha sido identificado en los modelos multinivel: cuando la muestra es pequeña el supuesto de distribución normal no se cumple (Cora Mass y JoopJ. Hox, "Robustness issues in multilevel regression analysis", Statistica Neerlandica, vol. 58, núm. 2 (2004), pp. 127-137; Rien Van der Leeden, Erik Meijer y Frank M. Busing, "Resampling multilevel models", en Jan de Leeuw y Erik Meijer (eds.), Handbook of multilevel analysis, Nueva York, Springer, 2008, pp. 401-433), y por tanto los errores estándar tienen un sesgo (recordando que en el modelo multinivel cada nivel genera sus propios residuos). Este problema afecta particularmente a quienes estiman los efectos aleatorios del modelo (que calculan diferencias entre grupos). Mass y Hox (art. cit.) encuentran que cuando el número de grupos es menor a treinta, los errores estándar es- 
variables en cada uno de los países se recurrirá al modelo de regresión multinivel con efectos aleatorios y errores estándar robustos. ${ }^{54}$ Con fines descriptivos se presenta a continuación la mediana del voto ideológico en los países y a nivel latinoamericano en cada ronda del Latinobarómetro (en la gráfica 2 se expone también, en línea punteada, el ajuste exponencial de ese indicador). ${ }^{55}$

La gráfica muestra que Venezuela, Bolivia y Ecuador son los países con intención de voto más a la izquierda de la región (gracias a lo cual sus gobernantes son de ese ámbito del espectro ideológico desde hace más de una década) y que Guatemala y Paraguay se caracterizan por tener los electores más orientados a la derecha (no obstante lo cual pudieron ser parte del giro a la izquierda, aunque sólo por un periodo breve). En general, son mayoría las naciones con voto de

tán subestimados en 15 por ciento. Una solución que se da este problema es utilizar errores estándar robustos que hacen al modelo menos dependiente del supuesto de distribución normal. En su análisis muestran que utilizar errores estándar en el modelo multinivel aumenta el poder de cobertura de los intervalos de confianza para los efectos aleatorios. Por ello, utilizamos errores estándar robustos en nuestras estimaciones.

${ }^{54}$ Para analizar el efecto de las variables independientes por país empleamos modelos de efectos aleatorios clusterizados por año, que permiten controlar por los cambios en el tiempo que experimenta cada unidad. Además, optamos por efectos aleatorios debido a que las variables macro son muy estables en el tiempo (Jeffrey M. Wooldridge, Introductory Econometrics: A Modern Approach, Mason Ohio, South-Western Cengage Learning, 2013). Utilizar un modelo de efectos fijos haría que estas variables de interés desaparecieran del modelo (debido a que cambian poco); en cambio, al utilizar efectos aleatorios, estas variables se mantienen en el modelo. Lo anterior debido a que el modelo asume que los factores no observables no están correlacionados con las variables independientes.

${ }^{55}$ Resulta imposible mostrar los descriptivos de los partidos políticos, debido a que en el periodo de estudio se cuenta con información de intención de voto hacia 506 partidos en los 18 países analizados (28.1 partidos en promedio por cada país). Uruguay y Honduras son los países en que se observa menos partidos (siete en ambos casos), en tanto que en Argentina y Bolivia hay más de 40 partidos hacia los cuales los electores manifiestan preferencia electoral. 
GRÁFICA 1

Mediana de la medición ideológica de intención de voto en América Latina (por países)

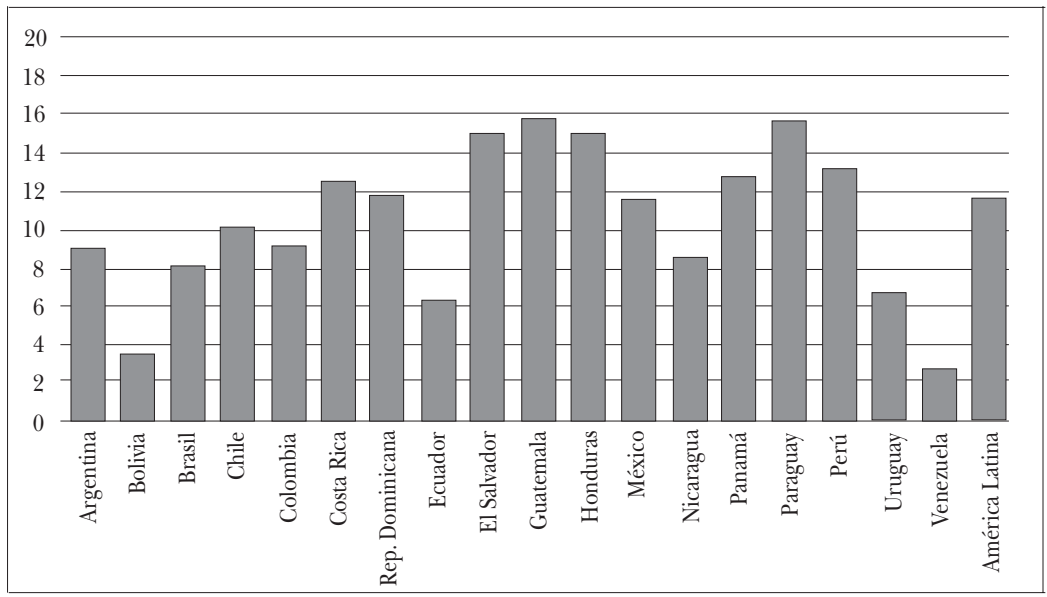

Fuente: elaboración propia con base en datos de Latinobarómetro (1996-2016).

derecha (con mediana mayor a 10, la mitad de la escala de medición), por lo que se puede afirmar que el votante latinoamericano mediano es de centro derecha (así lo muestra la última barra de la ilustración). La gráfica 2 permite apreciar los giros a la izquierda y a la derecha del electorado en América Latina. Si bien la mediana de la medición ideológica de Baker y Greene es mayor a 10 en casi todos los años, se observa con claridad que desde fines de los noventa hay una tendencia a votar cada vez más por los partidos de izquierda, situación que se revierte desde fines de la década pasada. Esto revela que, en términos de intención de voto, los mencionados giros en realidad se iniciaron varios años antes de lo que señala la literatura. Los cambios en el tiempo del voto ideológico no son radicales, como tal vez podría esperarse (en especial si consideramos cuán dominante fue el giro a la izquierda en cuanto a los presidentes electos de esa corriente), pero son lo suficientemente importantes como para inclinar 


\section{GráficA 2}

Mediana de la medición ideológica de intención de voto en América Latina (por cada ronda de Latinobarómetro)

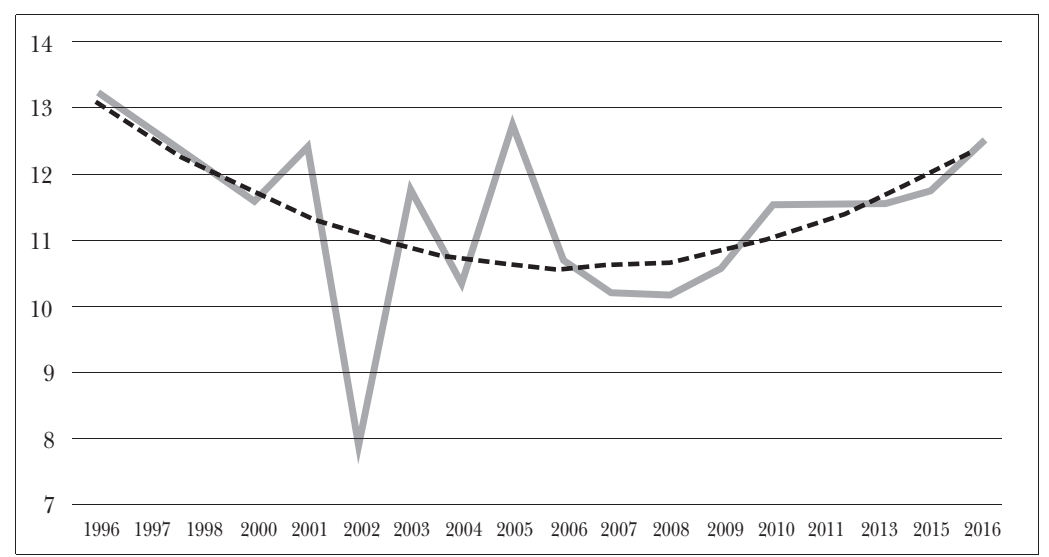

Fuente: elaboración propia con base en datos de Latinobarómetro (1996-2016).

el péndulo que indica qué ideología es la que más gobierna en los países hacia uno u otro lado.

\section{Resultados}

A continuación, se exponen los resultados de los modelos de regresión para toda América Latina (los tres primeros) y para sus dieciocho países. El modelo AL 1 considera únicamente los indicadores de país como variable explicativa. Esto es importante para estimaciones posteriores sobre cuánto contribuyen las variables micro y macro a la explicación. El modelo AL 2 considera las variables micro, es decir, aquellas que están agregadas a nivel individual. Finalmente, el modelo AL 3 agrega las variables macro a nivel país. En el cuadro 3 se exponen los coeficientes de los modelos de regresión y los errores estándar (estos últimos en paréntesis). 


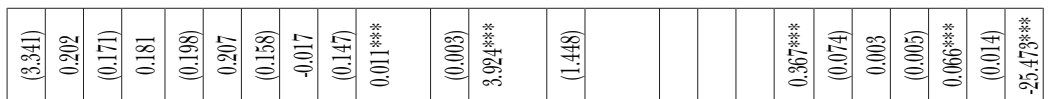

\begin{tabular}{|c|c|c|}
\hline 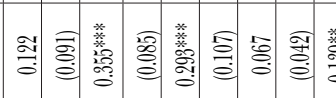 & 圈喜 & : \\
\hline 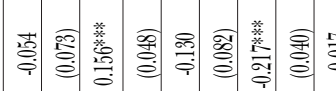 & & \\
\hline
\end{tabular}

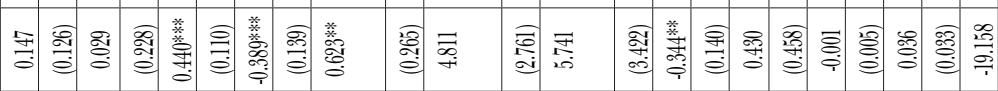

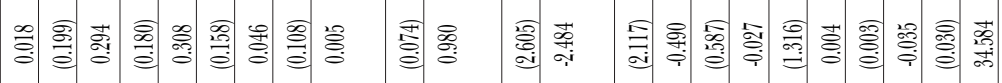

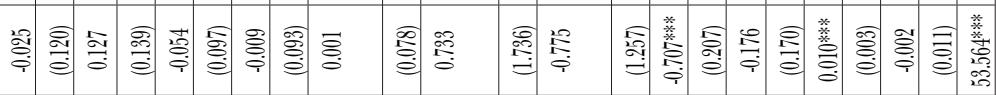

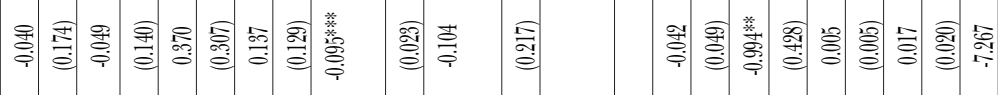

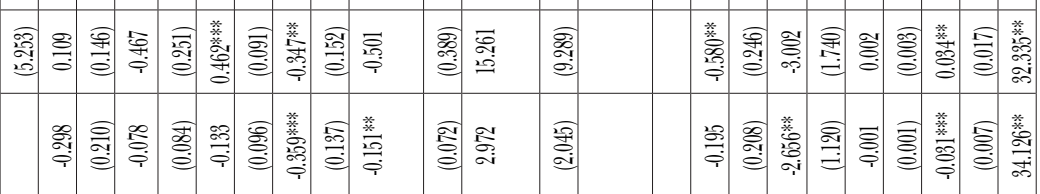

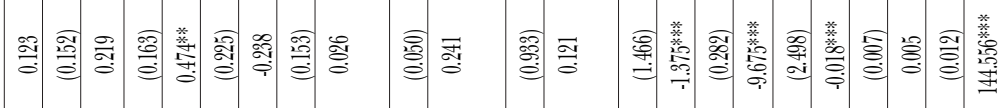

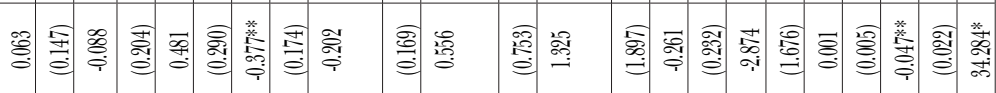

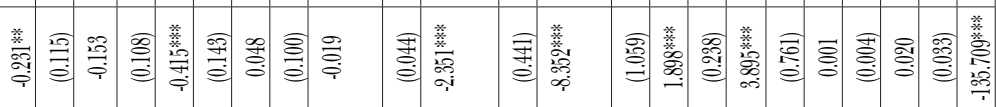

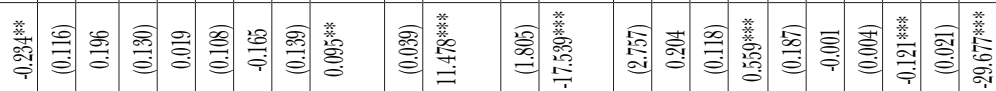

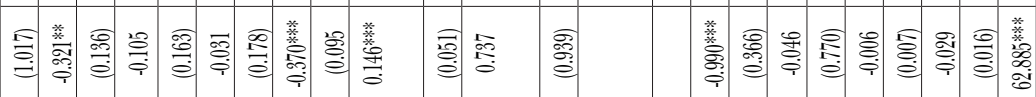

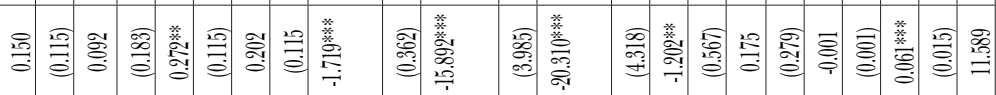

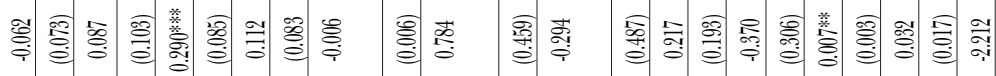

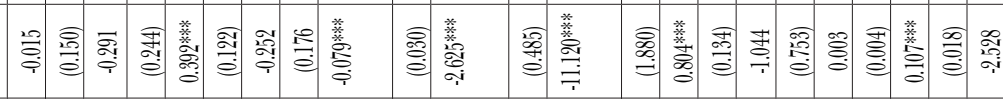

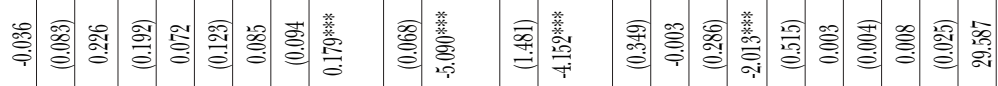

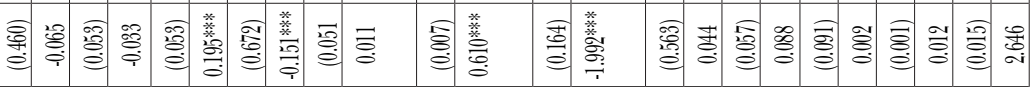

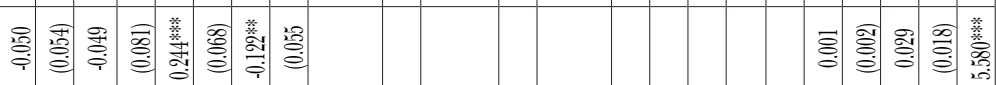


Inicialmente se analizarán los resultados de los tres modelos en que se estudia América Latina en conjunto. La constante de AL 1 corresponde a la gran media, lo que indica que, entre países e individuos, el voto ideológico medio del latinoamericano es de 11.26 (centro derecha). Sin embargo, los países varían con respecto a este valor, como lo indica la varianza del nivel 2, lo que significa que existen diferentes interceptos para cada país. A partir de esos dos coeficientes, se calcula la correlación intraclase, indicador que nos permite saber cuánto de la varianza total de la variable dependiente se debe a las diferencias entre países. La correlación intraclase se estima de la siguiente forma:

$$
\hat{p}=\hat{T}_{00} / \hat{T}_{00}+\hat{\sigma}^{2}
$$

Donde $\hat{T}_{00}$ indica la constante para el grupo de agregación más alto (país) y $\hat{\sigma}^{2}$ se refiere a la varianza del nivel de agregación 1. Esto es $\hat{p}=5.10 / .10+19.66=0.205$. Este resultado apunta a que, en principio, 20.5 por ciento de la variación en el voto ideológico se explica por diferencias entre países.

El modelo AL 2 agrega las variables a nivel individual. Los resultados muestran que conforme los latinoamericanos tienen una percepción negativa del desempeño económico, tienden a votar más por las opciones de derecha. ${ }^{56} \mathrm{En}$ términos sustantivos, un aumento de una unidad en la escala (por ejemplo, pasar de una percepción de que la situación económica es "muy buena" a una "buena") tiene un efecto de 0.27 en la variable dependiente. Por otro lado, la insatisfacción con la democracia también está vinculada con el voto por la derecha, ya que pasar de estar "muy satisfecho" a "nada satisfecho" con la democracia conlleva a un incremento de 0.66 en el voto ideológico. De igual manera, la desconfianza en el Congreso está positivamente relacionada con el voto por la derecha: el modelo AL 2 apunta a que pasar de "mucha" a

${ }^{56}$ Remmer, art. cit. y Dosek, art. cit., llegaron al mismo resultado. 
"ninguna" confianza en el Congreso está acompañado de un deslizamiento de 0.57 en la intención de voto en el espectro ideológico. Estos resultados no prueban que los argumentos sobre el giro a la derecha al respecto sean correctos (ya que éstos parten del supuesto de que está gobernando la izquierda y nuestro modelo controla por la orientación ideológica del gobierno) y son congruentes con que el electorado latinoamericano es, de forma predominante, de centro derecha, ya que resulta lógico que el mismo se incline principalmente por esas opciones políticas cuando no está satisfecho con la economía, la democracia ni con el desempeño de las instituciones políticas en su país.

El modelo AL 2 también muestra que la autoubicación ideológica es un buen predictor del voto. ${ }^{57}$ Así, un aumento de una unidad en la escala izquierda-derecha está asociada con un incremento de 0.46 en nuestra escala de intención de voto. Asimismo, las personas con una percepción positiva de Estados Unidos y con auto propio tienden a inclinarse por la derecha, con un incremento de 1.08 y de 0.24 en la variable dependiente, respectivamente. Ello indica que el anti (o pro) norteamericanismo sí influye en el voto de los latinoamericanos y que en América Latina existe un voto orientado por la clase social, y las clases altas tienden a apoyar a candidatos que no buscan una redistribución económica (lo que brinda respaldo al enfoque sociológico del comportamiento electoral). Finalmente, las variables micro muestran que los hombres están ligeramente inclinados a la izquierda (con un coeficiente de -0.12), lo que coincide con lo encontrado por Mainwaring et al. y por Morgan ${ }^{58}$ en su estudio del votante latinoamericano.

${ }^{57}$ Lo que confirma los hallazgos de Queirolo, op. cit. y de Dosek, Loc. cit.

58 Mainwaring op. cit., 2015 y Jana Morgan, "Gender and the Latin American Voter", en Ryan Carlin, Matthew M. Singer y Elizabeth J. Zechmeister (eds.), The Latin American Voter: Pursuing Representation and Accountability in Challenging Contexts, Ann Arbor, University of Michigan Press, 2015. 
Con la información de AL 1 y AL 2 podemos estimar qué tanto poder explicativo tienen las variables individuales sobre las variaciones en el voto ideológico entre países. Para ello se comparan la varianza en el resultado del intercepto aleatorio de AL 1 con los efectos aleatorios de AL 2. Esto se expresa de la siguiente manera:

$$
R_{1}^{2}=1-\frac{\operatorname{Var} M 2(Y)}{\operatorname{Var} M 1(Y)}=1-\frac{3.89+17.72}{5.10+19.66}=12.6
$$

Este coeficiente indica que las variables individuales explican el 12.6 por ciento de las variaciones en el voto ideológico entre países.

En AL 3 incluimos las variables agregadas a nivel país. El modelo muestra que "situación económica del país" y "satisfacción con la democracia" dejan de ser significativas al incluir las variables macro. El resto de las variables de nivel individual continúan siendo significativas. En este modelo se observa que un decrecimiento de uno por ciento en el PIB está asociado con un deslizamiento hacia la derecha de los votantes del país de 0.41 en la escala de voto ideológico (lo que indica, nuevamente, que en tiempos de dificultades económicas los electores prefieren las opciones de derecha). AL 3 también muestra que, contrario a lo esperado, cuando hay gobiernos subnacionales de izquierda, la media del país se corre a la derecha en 0.91 , lo que indica que el éxito electoral a nivel nacional no depende de que los partidos sean exitosos a nivel subnacional. ${ }^{59}$ Asimismo, el número efectivo de

${ }^{59}$ Juan Linz ("Democracia presidencial o parlamentaria ¿Qué diferencia implica?", en Juan Linz y Arturo Valenzuela (comps.), La crisis del presidencialismo, Madrid, Alianza, 1994, pp. 25-143) señaló que un rasgo problemático de los sistemas presidenciales es la debilidad de los partidos en relación con las figuras políticas, que ocasiona que pueda llegar a la presidencia alguien que no tiene trayectoria política previa o que haya construido un partido a su propia medida. En ese sentido, bien podría darse que un candidato se imponga en un entorno de autoridades subnacionales muy adverso. 
partidos (NEP) está asociado positivamente con un aumento en la intención de voto por la derecha; cuando aumenta en una unidad el NEP, el país presenta un incremento de 0.61 en el eje izquierda-derecha. ${ }^{60}$ Por otro lado, cuando la izquierda gobierna el país, las preferencias electorales tienden a inclinarse hacia ese lado del espectro ideológico (lo mismo ocurre para la derecha), lo que tiene relación con el hecho de que los partidos oficialistas gozan de una ventaja importante para la competencia política y que, para lograr alternancias, usualmente se tiene que remar a contracorriente. ${ }^{61}$ Esta variable tiene un efecto fuerte, ya que los países gobernados por la izquierda se deslizan en 1.99 puntos hacia ese lado de la escala ideológica.

Al comparar los modelos AL 2 y AL 3 podemos estimar qué porcentaje de las variaciones en el voto ideológico entre países explican las variables macro. Esto se obtiene de la razón entre la varianza del nivel 2 en AL 2 y la varianza del nivel 2 en AL 3, lo que se expresa así:

$$
R=\mathrm{T}_{00}{ }^{\mathrm{m} 2} / \mathrm{T}_{00}{ }^{\mathrm{m} 3}=3.89 / 4.40=88.4
$$

Esto quiere decir, que las variables macro explican el 88.6\% de las variaciones en el voto ideológico entre países. En otras palabras, las variables macro son las que tienen ma-

${ }^{60}$ En América Latina la media del número efectivo de partidos (NEP) es 3.08, lo que significa que predomina el multipartidismo. Dado ese contexto, una mayor fragmentación perjudica a las opciones de izquierda, lo que podría significar que éstas saldrían beneficiadas si presentan pocas (o una) candidatura(s). Esto es algo que debe estudiarse en mayor profundidad.

${ }^{61}$ Adam Przeworski (Democracy and the limits of self-government, Cambridge, University Press, 2010), muestra que el poder de quien ejerce la presidencia es tan grande que rara vez pierde la reelección. El registro en América Latina a fines de 2018 indica que, de veintidós presidentes que buscaron reelegirse desde 1990, sólo dos no lo lograron: Daniel Ortega en Nicaragua, en 1990, e Hipólito Mejía en República Dominicana, en 2004. 
yor poder explicativo acerca de cómo varía entre las naciones el voto ideológico de los electores latinoamericanos.

Sólo nueve de las veinte variables introducidas en el modelo AL 3 resultan significativas, lo que indica que la satisfacción con la democracia, la institucionalización de la competencia política, la difusión regional a la izquierda, la delincuencia, el evangelismo, la desigualdad, la edad de los electores y su nivel educativo no son relevantes para explicar el voto ideológico. Sin embargo, esa interpretación debe ser cuidadosa, ya que todas las variables arrojan coeficientes significativos en al menos un país latinoamericano. Ello muestra que los resultados obtenidos están influidos por el nivel de agregación de los datos (país o región) y que los contextos nacionales importan mucho en la explicación del voto ideológico. Este hallazgo coincide con lo encontrado por Carlin et al. ${ }^{62}$ en The Latin American Voter, lo que los llevó a afirmar que en realidad no existe algo así como "el votante latinoamericano".

A continuación se expone la importancia que tienen las veinte variables que aparecen en los modelos de regresión, en función de: 1) en cuántos países exhiben relación significativa con el voto ideológico (en más de 10 se considera que la relevancia es alta, de 5 a 10 la relevancia es media, y de 1 a 4 es baja, ${ }^{63}$ y 2) si esa relación es congruente o no (para ser congruentes los coeficientes deben tener el mismo signo en al menos el 70 por ciento de los casos significativos) ${ }^{64}$ En negrillas aparecen las variables significativas del modelo AL 3.

El cuadro 3 revela que la mayoría de las variables que resultaron significativas en el modelo AL 3 tienen una relación congruente con el voto ideológico; es decir, lo que se mencionó para la región en conjunto sobre "escala izquier-

${ }^{62}$ Carlin, op. cit.

63 Para las variables agregadas que no hubieran podido ser incluidas en el modelo de regresión de algún país por problemas de colinealidad se aplica el mismo criterio, pero en porcentajes.

64 Aunque esta clasificación es arbitraria, resulta útil para distinguir qué variables resultan más y menos relevantes en la explicación del voto ideológico entre los países, y si hay constancia en esa relación. 
da-derecha”, "opinión sobre Estados Unidos”, "confianza en el Congreso", "auto", "sexo”, "ideología del gobierno" y "gobiernos subnacionales de izquierda" es pertinente para casi todos los casos en que sus coeficientes resultan significativos. Sin embargo, no todas ellas son igualmente relevantes para explicar nuestra variable dependiente en los países, de tal modo que sólo las dos primeras son importantes en la mayoría de las naciones. Por lo anterior podría afirmarse que si algo caracteriza al votante latinoamericano es que su decisión electoral está fuertemente influida por su ideología y por su anti (o pro) norteamericanismo. ${ }^{65}$ Las variables "crecimiento del PIB" y "Número efectivo de partidos" no muestran congruencia en su relación con el voto ideológico en los países, a pesar de ser significativas en el modelo AL 3. Ello podría deberse a que el crecimiento económico nacional suele ser volátil de un año a otro, en especial cuando es muy dependiente de factores externos, como es el caso de las naciones latinoamericanas, y el agregado regional de AL 3 recoge una relación más amplia y estable entre esas variables. De manera similar, la incongruencia de "número efectivo de partidos" podría deberse a que no presenta grandes cambios en los países, pero sí entre ellos, por lo que AL 3 logra captar una relación también más amplia con el voto ideológico. ${ }^{66}$

65 La autoubicación ideológica de los latinoamericanos prácticamente no ha cambiado entre 1996 y 2016, ya que en todos esos años la mediana y la moda de la escala de medición es 5 , lo que significa que en términos ideológicos los habitantes de la región son de centro (no así en cuanto a su preferencia electoral, que se ha visto que es de centro derecha). Por otro lado, entre 2001 y 2008, la opinión negativa sobre Estados Unidos aumentó en más de 15 puntos porcentuales; después esa tendencia se revirtió. No estamos en condiciones de señalar por qué sucedió ese cambio, pero es posible que la imagen internacional negativa de George W. Bush y positiva de Barack Obama tenga algo que ver con ello.

66 Sólo en los casos de Argentina, Ecuador y Bolivia la desviación estándar de "número efectivo de partidos" es mayor a la de la región en conjunto. 


\section{Cuadro 3}

Relevancia y congruencia de las relaciones significativas del cuadro 2

\begin{tabular}{|c|c|c|c|c|}
\hline & & \multicolumn{3}{|c|}{ Relevancia en los 18 países } \\
\hline & & Alta & Media & Baja \\
\hline $\begin{array}{l}\text { Tipo de } \\
\text { relación }\end{array}$ & Consistente & $\begin{array}{l}\text { Escala izquierda- } \\
\text { derecha } \\
\text { Opinión sobre EE.uU. }\end{array}$ & $\begin{array}{l}\text { Confianza en el Congreso } \\
\text { Auto } \\
\text { Sexo } \\
\text { Ideología del gobierno } \\
\text { Gobiernos subnacionales de } \\
\text { izquierda } \\
\text { Índice de Gini } \\
\text { Años de estudio }\end{array}$ & $\begin{array}{l}\text { Victimización } \\
\text { Evangelismo }\end{array}$ \\
\hline & Inconsistente & Difusión izquierda & $\begin{array}{l}\text { Crecimiento del PIB } \\
\text { Número efectivo de partidos } \\
\text { Situación económica del país } \\
\text { Satisfacción con la } \\
\text { democracia } \\
\text { Polity } \\
\text { Volatilidad electoral } \\
\text { PIB per cápita } \\
\text { Edad }\end{array}$ & \\
\hline
\end{tabular}

Fuente: elaboración propia.

El enfoque sociológico sobre el comportamiento electoral tiene buen grado de corroboración en los países de América Latina. Aunque "auto", la variable con que se lo mide, es de relevancia media, resulta congruente en su relación con el voto ideológico. ${ }^{67}$ Esto no alcanza para afirmar que el vo-

${ }^{67}$ Entre 1998 y 2006 la gente con auto propio pasó de 35.8 a 23 por ciento de la población (disminuyó en casi 13 puntos); después aumentó hasta alcanzar 31.5 por ciento en 2016. Ello puede tener relación con los ciclos de expansión y contracción de la economía, en que el porcentaje de gente con ingresos suficientes para adquirir un automóvil (es decir, para pertenecer a un sector relativamente privilegiado de la población con capacidad de adquirir un bien que otorga cierta distinción) aumenta o se reduce. 
tante latinoamericano está orientado en su decisión electoral por sus características sociales, pero sí para señalar que la clase social es en buena medida importante para explicar el voto ideológico. Otras variables con relevancia media y relación congruente son el "índice de Gini" y los "años de estudio”, y los signos de sus coeficientes indican, por un lado, que los aumentos en la desigualdad llevan a votar por los candidatos de izquierda y, por otro, que el incremento en el nivel educativo se relaciona con mayor voto por la derecha (lo cual es pertinente para la mayoría de los países en los que esos coeficientes son significativos). La primera relación es esperable dado que los partidos de izquierda suelen precisamente cuestionar los altos niveles de desigualdad existentes, en tanto que la segunda no tiene explicación teórica a partir de los enfoques y trabajos revisados. ${ }^{68}$ Los cambios en estas variables también pesan en el voto ideológico de buena parte de los países, aunque no se puede afirmar que su importancia sea general para toda la región. ${ }^{69}$

"Victimización" y "evangelismo" tienen baja relevancia en los países, pero su relación es congruente en aquellos ca-

${ }^{68}$ Los principales planteamientos teóricos sobre el comportamiento electoral (no así sobre el comportamiento político o sobre el partidismo) y los estudios previos citados en este trabajo no consideran la influencia del nivel educativo sobre el voto ideológico. Aquí se incluyó como variable de control, pero queda claro que el análisis de sus efectos electorales debe realizarse con mayor profundidad.

${ }^{69} \mathrm{El}$ índice de Gini muestra históricamente valores muy altos en América Latina, pero ha ido cayendo a partir de 2003, cuando alcanzó un valor promedio de 0.54. En 2009 se ubicó por primera vez por debajo de 0.5 y en 2016 es igual a 0.46 . Esta disminución de la desigualdad tiene que ver con el buen desempeño económico de la mayoría de los países en el periodo 2004-2014, en que los precios internacionales de materias primas se mantuvieron al alza. Por otro lado, el nivel educativo cayó a inicios de la década pasada de un promedio de 11.03 años completados en 1998 a 8.81 en 2006 (más de dos años promedio de retroceso). Este indicador luego fue aumentando y en 2016 registra un valor de 9.97. Así, en esta variable también se observa el efecto de la recesión económica de inicios de la década pasada y de la recuperación posterior (lo que significaría que durante las crisis mucha gente abandona sus estudios). 
sos en que sus coeficientes resultan significativos, en el sentido de que su aumento tiende a beneficiar el voto por las opciones de derecha. ${ }^{70}$ No puede señalarse que ambas variables contribuyan a explicar el voto ideológico en la mayoría de las naciones de la región, pero su congruencia sí puede resultar importante en el agregado regional a futuro, en especial si ambas variables tienden a aumentar en el tiempo. ${ }^{71}$ El efecto de todas las demás variables, es decir, de las que muestran una relación incongruente en el cuadro 2 y no significativa en el modelo AL 3, depende del contexto específico de los países. En ese sentido, si bien los planteamientos teóricos que señalan su importancia no pueden rechazarse, la explicación de cómo influyen en el voto ideológico no puede generalizarse y sólo podría determinarse mediante estudios de caso específicos. Destaca que la percepción sobre la economía y la satisfacción con la democracia, que son factores causales muy mencionados por la literatura de los giros a la izquierda y a la derecha, muestren incongruencia en su relación con el voto ideológico (lo que podría significar que los electores castigan a sus gobernantes por las crisis económicas y por su descontento democrático, independendientemente de la corriente ideológica a la que éstos pertenezcan). Así también se explica que un aspecto tan importante para la ciencia política como la institucionalización del sistema de partidos, por un lado, y la institucionalización de la competencia política, por otro, no exhiban una relación clara con la variable dependiente. Ello indica que la utilidad explicativa de algunas teorías varía de unos países a otros, en función de si se cumplen o no los supuestos de los que parten. ${ }^{72}$

${ }^{70}$ Ambos planteamientos son de Lissandry, art. cit.

${ }^{71}$ En 1996 sólo 10 por ciento de los encuestados manifestaba pertenecer a alguna de las expresiones religiosas protestantes, y a partir de 2013 se observan porcentajes que duplican ese valor. Ese ritmo de cambio podría resultar relevante para el comportamiento electoral futuro de los votantes.

${ }^{72}$ Que es algo en lo que Mainwaring y Torcal, art. cit., y Torcal, op. cit. insisten en relación con los sistemas de partidos latinoamericanos. 
Por último, puede observarse que también hay variación en los coeficientes de determinación en los dieciocho modelos de regresión expuestos por países, lo que nuevamente tiene que ver con la amplia heterogeneidad que, como se ha mencionado, caracteriza a la región. En particular destaca que los modelos tienen alta capacidad explicativa para Uruguay, Chile y Bolivia, y baja para Panamá y México. Para estos últimos se impone la necesidad de profundizar lo señalado aquí sobre el voto ideológico con estudios de caso. Al respecto, es importante mencionar que el análisis exhaustivo de los resultados del cuadro 2 para cada uno de los países excede lo que este trabajo puede ofrecer en extensión y en profundidad. El tipo de aproximación que pensamos más conveniente para fines de investigación de las características del voto ideológico en América Latina y de sus principales variantes es el que privilegia el estudio a nivel de las variables, de su relevancia y congruencia explicativa, que es lo que se ofrece en este texto. Sin duda el cuadro 2 despierta muchas interrogantes y, justamente, queremos motivar a que se realicen estudios de caso y de $n$ pequeña sobre el fenómeno para profundizar el conocimiento de las tendencias y divergencias aquí mencionadas. ${ }^{73}$

\section{LA PERTENENCIA INDÍGENA}

En el apartado teórico se vio que son muy pocos los autores ${ }^{74}$ que han estudiado el efecto de la pertenencia indígena sobre el comportamiento electoral en América Latina. En relación con dicho factor, en este trabajo nos hemos enfrentado a dificultades tanto en la varianza de la variable "lengua materna autóctona" (que es casi una constante a nivel regional)

${ }^{73}$ La base de datos construida para este artículo puede ser explotada en muchas otras investigaciones. Por ello, la ponemos a disposición en la siguiente liga: https://www.dropbox.com/sh/qmegutmz6qn877n/AACU d9021EFqUHashAu0zQZUa?dl=0

${ }^{74}$ Dosek, art. cit. y Moreno, op. cit. 
como en las rondas del Latinobarómetro en que ésta fue incluida. De haberla considerado en los modelos del cuadro 2, se hubiera perdido una cantidad considerable de datos y el beneficio analítico hubiera sido nulo (ver la nota al pie 29). Sin embargo, hemos decidido incluir esta variable en un análisis adicional para los países con mayor porcentaje de población indígena (en función de su lengua materna), a saber, Bolivia, Guatemala, Paraguay y Perú. Creemos que esta decisión es apropiada dado que la alternativa sería excluir totalmente la pertenencia indígena del estudio sobre el voto ideológico. Los modelos que se exponen a continuación son casi idénticos a los del cuadro 2, con la única diferencia de la inclusión de "lengua materna autóctona".

\section{Cuadro 4}

Determinantes del voto ideológico en Bolivia,

Guatemala, Paraguay y Perú, 2002-2016

(variable dependiente en escala de 1 a 20$)^{a}$

\begin{tabular}{|l|c|c|c|c|}
\hline & Bolivia & Guatemala & Paraguay & Perú \\
\hline Situación económica del país & $0.744^{* * *}$ & 0.029 & -0.187 & -0.214 \\
\hline & $(0.202)$ & $(0.130)$ & $(0.122)$ & $(0.130)$ \\
\hline Crecimiento del pIB & 0.170 & -0.009 & 0.145 & -0.103 \\
\hline & $(0.212)$ & $(0.084)$ & $(0.223)$ & $(0.095)$ \\
\hline Satisfacción con la democracia & $0.807^{* * *}$ & $0.356^{* *}$ & -0.035 & -0.002 \\
\hline & $(0.196)$ & $(0.180)$ & $(0.144)$ & $(0.118)$ \\
\hline Confianza en el Congreso & 0.232 & -0.092 & -0.005 & -0.047 \\
\hline & $(0.170)$ & $(0.137)$ & $(0.190)$ & $(0.085)$ \\
\hline Polity & $-2.795^{* * *}$ & & 2.920 & \\
\hline & $(0.275)$ & & $(2.031)$ & \\
\hline Escala izquierda-derecha & $0.417^{* * *}$ & 0.066 & $0.310^{* * *}$ & $0.205^{* * *}$ \\
\hline & $(0.072)$ & $(0.064)$ & $(0.067)$ & $(0.038)$ \\
\hline Opinión sobre EEuU & $1.965^{* * *}$ & 0.051 & 0.206 & $0.534^{* * *}$ \\
\hline & $(0.168)$ & $(0.225)$ & $(0.126)$ & $(0.174)$ \\
\hline Difusión izquierda & $-4.952^{* * *}$ & & & \\
\hline & $(1.638)$ & & & \\
\hline Gobiernos subnacionales de izquierda & & & & \\
\hline & & & & \\
\hline
\end{tabular}




\section{Cuadro 4 (conclusión) \\ Determinantes del voto ideológico en Bolivia, Guatemala, Paraguay y Perú, 2002-2016

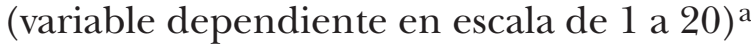

\begin{tabular}{|c|c|c|c|c|}
\hline Victimización & 0.070 & 0.139 & 0.028 & 0.179 \\
\hline & $(0.183)$ & $(0.167)$ & $(0.230)$ & $(0.150)$ \\
\hline \multirow[t]{2}{*}{ Evangelismo } & -0.394 & 0.221 & 0.329 & 0.065 \\
\hline & $(0.229)$ & $(0.171)$ & $(0.204)$ & $(0.258)$ \\
\hline \multirow[t]{2}{*}{ Auto } & 0.219 & $0.499 * *$ & $0.377^{* *}$ & $0.496^{* * *}$ \\
\hline & $(0.182)$ & $(0.239)$ & $(0.187)$ & $(0.103)$ \\
\hline \multirow[t]{2}{*}{ Lengua materna autóctona } & $-1.936^{* * *}$ & -0.008 & 0.023 & $-1.481 * * *$ \\
\hline & $(0.260)$ & $(0.307)$ & $(0.364)$ & $(0.301)$ \\
\hline \multirow[t]{2}{*}{ Sexo } & -0.093 & -0.265 & 0.048 & $-0.458^{* * *}$ \\
\hline & $(0.186)$ & $(0.155)$ & $(0.131)$ & $(0.151)$ \\
\hline \multirow[t]{2}{*}{ Volatilidad electoral } & $0.128 * * *$ & 0.025 & & $0.645^{* *}$ \\
\hline & $(0.035)$ & $(0.050)$ & & $(0.264)$ \\
\hline \multirow[t]{2}{*}{ Número efectivo de partidos } & $-7.606 * * *$ & 0.279 & & 5.103 \\
\hline & $(1.952)$ & $(0.938)$ & & $(2.745)$ \\
\hline \multirow[t]{2}{*}{ Ideología del gobierno } & $-25.769 * * *$ & 0.047 & -3.129 & 6.006 \\
\hline & $(6.217)$ & $(1.478)$ & $(2.883)$ & $(3.402)$ \\
\hline \multirow[t]{2}{*}{ Índice de Gini } & $0.649 * * *$ & $-1.375^{* * *}$ & -0.481 & $-0.354 * *$ \\
\hline & $(0.075)$ & $(0.282)$ & $(0.594)$ & $(0.143)$ \\
\hline \multirow[t]{2}{*}{ PIB per cápita } & $2.053 * * *$ & $-9.694 * * *$ & -0.032 & 0.433 \\
\hline & $(0.576)$ & $(2.497)$ & $(1.366)$ & $(0.462)$ \\
\hline \multirow[t]{2}{*}{ Edad } & 0.010 & $-0.018 * *$ & 0.004 & 0.000 \\
\hline & $(0.005)$ & $(0.007)$ & $(0.004)$ & $(0.005)$ \\
\hline \multirow[t]{2}{*}{ Años de estudio } & $0.064 * * *$ & 0.010 & -0.038 & 0.029 \\
\hline & $(0.015)$ & $(0.010)$ & $(0.030)$ & $(0.034)$ \\
\hline \multirow[t]{2}{*}{ Constante } & $17.484 * *$ & $147.119 * * *$ & 13.526 & -29.426 \\
\hline & $(7.080)$ & $(28.988)$ & $(39.134)$ & $(32.151)$ \\
\hline $\mathrm{R}^{2}$ & 0.362 & 0.166 & 0.200 & 0.164 \\
\hline & & & & \\
\hline
\end{tabular}

** Significativo al $95 \%$

*** Significativo al $99 \%$

a Algunas variables no presentan resultado debido a problemas de colinealidad (en especial en países unitarios, donde la orientación ideológica de los gobiernos subnacionales suele ser la misma que la del gobierno central) o a que algunas son constantes en el periodo analizado. 
Los resultados del cuadro 4 muestran que en los países en que "lengua materna autóctona" resulta significativa (Bolivia y Perú), su influencia favorece las opciones de izquierda; ${ }^{75}$ no obstante, no puede señalarse que la pertenencia indígena produce en automático una orientación determinada en el voto. Al parecer, y como lo menciona Moreno, ${ }^{76}$ la división indígena necesita politizarse (algo en lo que líderes políticos y dirigentes sociales tienen un papel muy importante) para que el voto de ese sector de la población se oriente predominantemente en un sentido. ${ }^{77}$ Ahora bien, si consideramos que históricamente en América Latina tanto las fuerzas de un lado y otro del espectro ideológico han excluido a los indígenas y han vulnerado sus derechos, ¿por qué la activación de dicha división favorece a los candidatos de izquierda? Algunos estudios de caso indican que eso se debe al tipo de construcción política de los partidos de izquierda en los últimos veinte años, en que confluyeron líderes indigenistas y de la izquierda tradicional en un contexto de crisis institucional de los sistemas políticos, ${ }^{78}$ pero es una pregunta que estudios futuros comparados deben abordar.

${ }^{75}$ Loc. cit., estos autores obtienen los mismos hallazgos.

76 Moreno, Loc. cit.

${ }^{77} \mathrm{Al}$ analizar la formación y éxito de partidos étnicos, Salvador Martí i Puig ( "Las razones de presencia y éxito de los partidos étnicos en América Latina. Los casos de Bolivia, Ecuador, Guatemala, México, Nicaragua y Perú [1990-2005]”, Revista Mexicana de Sociología, vol. 70, núm. 4 ([2008], pp. 675-724) concluye algo similar: "los partidos étnicos no son el resultado natural o automático de la existencia de divisiones étnicas, culturales o lingüísticas en una sociedad, ni de que la población indígena sea mayoritaria”.

78 Véase Donna Lee Van Cott, "Los movimientos indígenas y sus logros: la representación y el reconocimiento jurídico en los Andes", América Latina Hoy, núm. 36 (2004), pp. 141-159 y Moira Zuazo, ¿Cómo nació el MAS? La ruralización de la política en Bolivia, La Paz, Fundación Ebert, 2009. 
218 Mario Alejandro Torrico Terán y Diego Solís Delgadillo FI LX-1

\section{Conclusiones}

En este trabajo se ha mostrado evidencia de la existencia de giros a la izquierda y a la derecha en el electorado latinoamericano, de que comenzaron algunos años antes de lo que la literatura comparada señala y de que los votantes en la región en conjunto y en la mayoría de los países son principalmente de centro derecha. También se ha revelado que el voto ideológico tiene una influencia fuerte de la propia identificación ideológica de las personas y por su anti (o pro) norteamericanismo. Son esas características las que describen al votante latinoamericano. La confianza en las instituciones políticas, la clase social, la orientación ideológica del gobierno, el sexo del elector y la orientación ideológica de los gobiernos subnacionales son también factores que pesan en la explicación del voto ideológico, por su relevancia y congruencia, aunque su importancia no es generalizada en América Latina. En consecuencia, el voto tenderá hacia la derecha en cualquiera de las siguientes situaciones (y hacia la izquierda cuando ocurre lo contrario): si el elector se ubica en esa corriente ideológica, tiene buena opinión sobre Estados Unidos, desconfía de las instituciones, pertenece a clases altas, es de sexo femenino, el gobierno en funciones es de esa corriente ideológica y existen gobiernos subnacionales de izquierda. Los bajos niveles de desigualdad y la escolaridad alta también orientan el voto en ese sentido en varios países, aunque "índice de Gini" y "años de estudio" no tienen relación significativa en el modelo latinoamericano.

El cuadro 3 revela que todas las variables explicativas consideradas en este trabajo resultan significativas en al menos uno de los modelos de regresión del cuadro 2, pero que la mayoría son o incongruentes en su relación con el voto ideológico o de relevancia baja. Ello refleja que América Latina es muy heterogénea y que los contextos nacionales tienen mucha importancia en el tipo de influencias que dichas variables ejercen. En particular, resalta que el efecto de factores económicos y políticos, muy destacados por la literatura sobre com- 
portamiento electoral, por los textos que analizan los giros en la región o por la propia ciencia política (que refieren la percepción sobre la economía, la satisfacción con la democracia, la competencia política o la institucionalización de los sistemas de partidos) es muy dependiente del contexto de cada país. En consecuencia, la relación entre éstos y el voto ideológico no tiene un sentido predominante en la región, lo que impide establecer cualquier tipo de generalización al respecto y obliga a profundizar su análisis a través de estudios de caso y de análisis comparados de $n$ pequeña. Por otro lado, los factores que destacan los autores del giro a la derecha (delincuencia y avance de los evangélicos) tienen baja relevancia, pero son constantes, lo que significa que, en los países en que sus coeficientes resultan significativos, son muy importantes para explicar el auge reciente de las preferencias electorales hacia esa corriente ideológica. En caso de que tiendan al alza los niveles de victimización y el porcentaje de gente de creencia religiosa protestante, esas variables podrían tener relevancia en el voto ideológico regional a futuro.

¿Qué ocasionó los giros a la izquierda y a la derecha en América Latina? La mala imagen de Estados Unidos en la década pasada sin duda contribuyó al auge de la izquierda en la región, y la creciente opinión favorable sobre ese país, que se produjo a partir de 2008, también pesó en que las fuerzas de derecha empezaran a recuperarse. La crisis económica de principios de la década pasada parece haber tenido, en buena medida, un rol indirecto al respecto, ya que propició un descenso social (observado en la disminución del porcentaje de personas con auto particular, en la reducción de los años de escolaridad promedio y en el aumento de la desigualdad) que favoreció a quienes en ese momento no estaban gobernando: las izquierdas. Además, su nueva condición de oficialistas hizo posible que en muchos casos conservaran el poder más de una década. Pero el ascenso social posterior impulsado por condiciones económicas prósperas tendió a beneficiar a candidatos de derecha, que no defienden la redistribución económica (o que la atacan abiertamente). 
Este relato general tiene muchas variantes nacionales. Por ejemplo, en los países con una población indígena importante, en que se ha logrado politizar esa división de las izquierdas, se han fortalecido mucho, a tal grado que en Bolivia un presidente indígena se mantiene en el poder desde hace trece años. Esperemos que en no mucho tiempo logremos un conocimiento amplio del voto ideológico en esos contextos nacionales.

\section{REFERENCIAS BIBLIOGRÁFICAS}

Antunes, Rui, "Theoretical models of voting behaviour", Exedra, núm. 4 (2010), pp. 145-170.

Arditi, Benjamin, "El giro a la izquierda en América Latina: ¿una política post-liberal?”, Ciências Sociais Unisinos, vol. 45, núm. 3 (2010), pp. 232-246.

Arkonada, Katu, “¿Fin de ciclo? La disputa por el relato", América Latina en Movimiento, núm. 510 (2015), pp. 11-16.

Arnold, Jason R. y David J. SAmuels, "Evidence from public opinion", en Steven Levitsky y Kenneth M. Roberts (eds.), The Resurgence of the Latin American Left, Baltimore, The Johns Hopkins University Press, 2011.

Baker, Andy y Kenneth F. Greene, "The Latin American Left's Mandate: Free-Market Policies and Issue Voting in New Democracies", World Politics, vol. 63, núm. 1 (2011), pp. 43-77.

Balassa, Bela et al., Hacia una renovación del crecimiento en América Latina, Washington, Institute for International Economics, 1986. BARTELs, Larry M., "The Study of Electoral Behavior", en Jan E. Leighley (ed.), The Oxford Handbook of American Elections and Political Behavior. Oxford, University Press, 2010, pp. 239-260.

Bartle, John y Paolo Belluca, "Introduction. Partisanship, social identity and individual attitudes", en John Bartle y Paolo Bellucci (eds.), Political parties and partisanship, Londres, Routledge, 2009.

Beasley-Murray, Jon, Maxwell A. Cameron y Eric Hershberg, "Latin America's Left Turns: A Tour D’Horizon", en Maxwell 
A. Cameron y Eric Hershberg (eds.), Latin America's Left Turns: Politics, Policies, and Trajectories of Change, Boulder, Lynne Rienner, 2010.

Berelson, Bernard R., Paul F. Lazarsfeld y William N. McPhee, Voting: A Study of Opinion Formation in a Presidential Campaign, Chicago, University of Chicago Press, 1954.

Blanco, Luisa y Robin Grier, "Explaining the Rise of the Left in Latin America”, Latin American Research Review, vol. 48, núm. 1 (2013), pp. 68-90.

Borón, Atilio, “¿Una nueva era populista en América Latina?”, en Martha Lucía Márquez, Eduardo Pastrana y Guillermo Hoyos (eds.), El Eterno Retorno del Populismo en América Latina y el Caribe, Bogotá, Pontificia Universidad Javeriana/clacso, 2012.

Burlacu, Diana, "Corruption and Ideological Voting", British Journal of Political Science, (2018), pp. 1-22, DOI:10.1017/S0007123 417000758.

Cameron, Maxwell A., "Latin America's Left Turns: beyond good and bad", Third World Quarterly, vol. 30, núm. 2 (2009), pp. 331-348.

Campbell, Angus et al., The American Voter, Nueva York, John Wiley \& Sons, 1960.

Carlin, Ryan, Matthew M. Singer y Elizabeth J. Zechmeister, "Introduction to the Latin American Voter", en Ryan Carlin, Matthew M. Singer y Elizabeth J. Zechmeister (eds.), The Latin American Voter: Pursuing Representation and Accountability in Challenging Contexts, Ann Arbor, University of Michigan Press, 2015.

Castañeda, Jorge, "Latin America's Left Turn", Foreign Affairs, vol. 85, núm. 3 (2006), pp. 28-43.

Cleary, Matthew R., "Explaining the Left's Resurgence”, Journal of Democracy, vol. 17, núm. 4 (2006), pp. 35-49.

Cohen, Mollie, Facundo E. Salles Kobilanski y Elizabeth J. Zechmeister, "Electoral Volatility in Latin America", The Journal of Politics, vol. 80, núm. 3 (2018) (en línea), Dor: 10.1086/697464.

Comisión Ecónomica para América Latina (CEPAL), Estudio Económico de América Latina y el Caribe 2001-2002, CEPAL, Santiago de Chile, 2002. 
Dosek, Tomás, “¿Por qué la gente vota a la izquierda? Clivajes, ideología y voto retrospectivo en Bolivia y Uruguay en perspectiva comparada”, DADOS-Revista de Ciências Sociais, vol. 57, núm. 3 (2014), pp. 773-815.

El-Erian, Mohamed A., "El ascenso de la derecha en América Latina”, La Nación, 12 de junio de 2016, https:/ / goo.gl/2gHcXC

Fiorina, Morris P., Retrospective Voting in American National Elections, New Haven, Yale University Press, 1981.

LaAkso, Markku y Rein TaAgePera, "Effective Number of Parties: A Measure with Application to West Europe", Comparative Political Studies, vol.12, núm. 1 (1979), pp. 3-27.

LACHAT, Romain, "The impact of party polarization on ideological voting”, Electoral Studies, vol. 27, núm. 4 (2008), pp. 687-698.

LACLAU, Ernesto, "La deriva populista y la centroizquierda latinoamericana”, Nueva Sociedad, núm. 205 (2006), pp. 56-61.

LANZARo, Jorge, "Gobiernos de izquierda en América Latina: entre el populismo y la socialdemocracia”, en Ernst Hillebrand (ed.), La izquierda en América Latina y Europa: nuevos procesos, nuevos dilemas, Uruguay, Friedrich Ebert Stiftung, 2007.

LANZARO, Jorge, "La 'tercera ola' de las izquierdas latinoamericanas: entre el populismo y la social-democracia”, Estudio/Working Paper, núm. 91, Uruguay, Universidad de la República, 2008.

Latinobarómetro, Análisis de datos (banco de datos en línea), http:/ / www.latinobarometro.org/latOnline.jsp

Levitsky, Steven y Kenneth M. Roberts, "Introduction: Latin America's 'Left Turn'. A framework for analysis", en Steven Levitsky y Kenneth M. Roberts (eds.), The Resurgence of the Latin American Left, Baltimore, The Johns Hopkins University Press, 2011.

LinZ, Juan, "Democracia presidencial o parlamentaria ¿Qué diferencia implica?", en Juan Linz y Arturo Valenzuela (comps.), La crisis del presidencialismo, Madrid, Alianza, 1994, pp. 25-143.

Lissandry, Gerardo, "Por qué 2017 puede ser clave en el giro hacia la derecha de América Latina”, BBC Mundo, 5 de enero de 2017, http://www.bbc.com/mundo/noticias-america-latina-38493148 
Londoño, Ernesto, Pascal Bonnefoy y Daniel Politi, "La victoria de Piñera refuerza el giro a la derecha en América Latina”, The New York Times, 17 de diciembre de 2017, https:/ / www.nytimes. com/es/2017/12/19/chile-pinera-america-latina-derecha/

LORA, Eduardo, "Las reformas estructurales en América Latina: Qué se ha reformado y cómo medirlo", Documento de trabajo del BID \# IDB-WP-346, 2012.

Lubbers, Marcel y Take Sipma, "Multi-level Modelling of Voting Behaviour", en Kai Arzheimer; Jocelyn Evans y Michael S. Lewis-Beck (eds.), The Sage Handbook of Electoral Behaviour, Londres, Sage, 2017, pp: 934-951.

LunA, Juan Pablo, "The Left Turns: Why They Happened and How They Compare", en Maxwell A. Cameron y Eric Hershberg (eds.), Latin America's Left Turns: Politics, Policies, and Trajectories of Change, Boulder, Lynne Rienner, 2010.

Macdonald, Laura y Arne Ruckert, "Post-Neoliberalism in the Americas: An Introduction", en Laura Macdonald y Arne Ruckert (eds.), Post-Neoliberalism in the Americas, Nueva York, Palgrave, 2009.

Mader, Matthias y Harald Schoen, "Ideological voting in context: The case of Germany during the Merkel era", en Harald Schoen et al. (eds.), Voters and Voting in Context: Multiple Contexts and the Heterogeneous German Electorate, Oxford, University Press, 2016.

Mainwaring, Scott, "The Left and the Mobilization of Class Voting in Latin America”, en Ryan Carlin, Matthew M. Singer y Elizabeth J. Zechmeister (eds.), The Latin American Voter: Pursuing Representation and Accountability in Challenging Contexts, Ann Arbor, University of Michigan Press, 2015.

Mainwaring, Scott y Mariano Torcal, "La institucionalización de los sistemas de partidos y la teoría del sistema partidista después de la tercera ola democratizadora”, América Latina Hoy, núm. 41 (2005), pp. 141-173.

Marshall, Monty G. y Ted Robert Gurr, Polity IV Project. Political Regime Characteristics and Transitions, 1800-2015. Dataset, Maryland, Centre for Systemic Peace, 2016. 
Martí I Puig, Salvador, "Las razones de presencia y éxito de los partidos étnicos en América Latina. Los casos de Bolivia, Ecuador, Guatemala, México, Nicaragua y Perú (1990-2005)", Revista Mexicana de Sociología, vol. 70, núm. 4 (2008), pp. 675-724.

Mass, Cora y Joop J. Hox, "Robustness issues in multilevel regression analysis", Statistica Neerlandica, vol. 58, núm. 2 (2004), pp. 127-137.

Matos, Daniel y Eduardo Molina, "Giro a la derecha y lucha de clases en Sudamérica”, Estrategia Internacional, núm. 29 (2016), pp. 9-25.

Modonesi, Massimo, "Fin de la hegemonía progresista y giro regresivo en América Latina. Una contribución gramsciana al debate sobre el fin de ciclo", Viento Sur, núm. 15 (2015), pp. 23-30.

Moreira, Constanza, "El largo ciclo del progresismo latinoamericano y su freno. Los cambios políticos en América Latina en la última década (2003-2015)", Revista Brasileira de Ciencias Sociais, vol. 32, núm. 93 (2017), pp. 1-28.

Moreno, Daniel E., "Ethnicity and Electoral Preferences in Latin America”, en Ryan Carlin, Matthew M. Singer y Elizabeth J. Zechmeister (eds.), The Latin American Voter: Pursuing Representation and Accountability in Challenging Contexts, Ann Arbor, University of Michigan Press, 2015.

Morgan, Jana, "Gender and the Latin American Voter", en Ryan Carlin, Matthew M. Singer y Elizabeth J. Zechmeister (eds.), The Latin American Voter: Pursuing Representation and Accountability in Challenging Contexts, Ann Arbor, University of Michigan Press, 2015.

Panizza, Francisco, "Unarmed Utopia Revisited: The Resurgence of Left-of-Centre Politics in Latin America", Political Studies, vol. 53, núm. 4 (2005), pp. 716-734.

Panizza, Francisco, "Nuevas izquierdas y democracia en América Latina”, Revista CIDOB d'Afers Internacionals, núm. 85/86 (2009), pp. 75-88.

Paramio, Ludolfo, "Giro a la izquierda y regreso del populismo", Nueva Sociedad, núm. 205 (2006), pp. 62-74.

Paramio, Ludolfo, "La izquierda en América Latina", Quórum, Revista de pensamiento iberoamericano, núm. 22 (2008), pp. 21-29. 
Pedersen, Mogens N., "The Dynamics of European Party Systems: Changing Patterns of Electoral Volatility", European Journal of Political Research, vol. 7, núm. 1 (1979), pp. 1-26.

Programa de las Naciones Unidas para el Desarrollo (PNUD), La democracia en América Latina. Hacia una democracia de ciudadanas y ciudadanos. El debate conceptual sobre la democracia, Buenos Aires, Alfaguara, 2004.

Oscarsson, Henrik y Sören Holmberg, "Issue Voting Structured by Left-Right Ideology", en Jon Pierre (ed.), The Oxford Handbook of Swedish Politics, Reino Unido, Oxford University Press, 2015.

Przeworski, Adam, Democracy and the limits of self-government, Cambridge, University Press, 2010.

QueIrolo, Rosario, The Success of the Left in Latin America, Notre Dame, University of Notre Dame Press, 2013.

Remmer, Karen L., "The Rise of Leftist-Populist Governance in Latin America: The Roots of Electoral Change", Comparative Political Studies, vol. 45, núm. 8 (2012), pp. 947-972.

SAder, Emir, El Nuevo Topo. Los caminos de la izquierda latinoamericana, Buenos Aires, Siglo XXI/clacso, 2009.

SANTANDER, Sebastián, "El 'giro a la izquierda' en América Latina: Fragmentación y recomposición de la geopolítica regional", Cuadernos sobre Relaciones Internacionales, Regionalismo y Desarrollo, vol. 4, núm. 7 (2009), pp. 17-38.

Silva, Eduardo, Challenging Neoliberalism in Latin America, Cambridge, Cambridge University Press, 2009.

Somuano, Fernanda y Reynaldo Ortega, "La identificación partidista de los mexicanos y el cambio electoral, 1994-2000", Foro Internacional, vol. 43, núm. 1 (2003), pp. 10-38.

Telles, Helcimara y Alejandro Moreno (coords.), El votante latinoamericano. Comportamiento electoral y comunicación política, México, Cesop, 2015.

Thwaites Rey, Mabel, "Después de la globalización neoliberal: ¿qué Estado en América Latina?”, Observatorio Social de América Latina, año XI, núm. 27 (2010), pp. 19-43.

Torcal, Mariano (coord.), Sistema de partidos en América Latina. Causas y consecuencias de su equilibrio inestable, Barcelona, Anthropos, 2015. 
Torrico, Mario (ed.), ¿Fin del giro a la izquierda en América Latina?, México, Flacso, 2017.

VAN CotT, Donna Lee, "Los movimientos indígenas y sus logros: la representación y el reconocimiento jurídico en los Andes", América Latina Hoy, núm. 36 (2004), pp. 141-159.

Van der Leeden, Rien, Erik Meijer y Frank M. Busing, "Resampling multilevel models", en Jan de Leeuw y Erik Meijer (eds.), Handbook of multilevel analysis, Nueva York, Springer, 2008, pp. 401-433.

Wiesehomeier, Nina y David Doyle, "Discontent and the Left Turn in Latin America", Political Science Research and Methods, vol. 1, núm. 2 (2013), pp. 201-221.

Weyland, Kurt, "The Performance of Leftist Governments in Latin America: Conceptual and Theoretical Issues", en Kurt Weyland; Raúl L. Madrid y Wendy Hunter (eds.), Leftist Governments in Latin America. Successes and Shortcomingst, Cambridge, University Press, 2010.

Williamson, John, "What Washington Means by Policy Reform", en John Williamson, Latin American. How much has happened?, Washington DC, Institute for International Economics, 1990.

Wooldridge, Jeffrey M., Introductory Econometrics: A Modern Approach, Mason Ohio, South-Western Cengage Learning, 2013.

World Bank, World Development Indicators (base de datos en línea), https://data.worldbank.org/data-catalog/world-development-indicators

ZuAzo, Moira, ¿Cómo nació el MAS? La ruralización de la política en Bolivia, La Paz, Fundación Ebert, 2009. 